\title{
Thermodynamics and Kinetics of Ring-Opening Polymerization
}

Andrzej Duda and Adam Kowalski

\section{1 \\ Introduction}

Cyclic monomers that have been polymerized via ring-opening encompass a variety of structures, such as alkanes, alkenes, compounds containing heteroatoms in the ring: oxygen [ethers, acetals, esters (lactones, lactides, and carbonates), and anhydrides], sulfur (polysulfur, sulfides and polysulfides), nitrogen [amines, amides (lactames), imides, $N$-carboxyanhydrides and 1,3-oxaza derivatives], phosphorus (phosphates, phosphonates, phosphites, phosphines and phosphazenes), or silicon (siloxanes, silaethers, carbosilanes and silanes). For the majority of these monomers, convenient polymerization conditions have been elaborated, that result in the controlled synthesis of the corresponding polymers [1-13].

The ability of a cyclic monomer to polymerize according to the ring-opening mechanism is determined by two equally important factors-the conversion of monomer molecules into macromolecules (of linear or more complex topologies) must be allowed both thermodynamically and kinetically. In practical terms this means that: (i) monomer-macromolecule equilibrium must be shifted to the righthand (macromolecule) side; and (ii) the corresponding polymerization mechanism should exist, that could enable conversion of the monomer molecules into the polymer repeating units, within the operable polymerization time (Equation 1.1).

The net equation of the polymerization process reads:

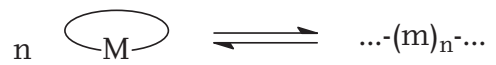

where $\mathrm{M}$ denotes the monomer molecule, and $\mathrm{m}$ is the macromolecule repeating unit derived from the $\mathrm{M}$ monomer; whereas an elementary reaction of the macromolecular chain growth can be written as:

$$
\ldots-(\mathrm{m})_{\mathrm{n}} \mathrm{m} *+\bigodot_{\mathrm{M}} \frac{k_{\mathrm{p}}}{{ }_{k_{\mathrm{d}}}} \ldots-(\mathrm{m})_{\mathrm{n}+1} \mathrm{~m}^{*}
$$


where $\mathrm{m} *$ denotes the active species, and $k_{\mathrm{p}}$ and $k_{\mathrm{d}}$ are the rate constants of propagation and depropagation, respectively.

Depending on the monomer and catalytic/initiating system and the nature of the resulting active species, a number of mechanisms can operate in the ringopening polymerization (ROP). The mechanisms most often employed include coordination, covalent, ionic (anionic or cationic), metathetic, radical and enzymatic. With regards to location of the active species, active chain-end or activated monomer mechanisms can be distinguished. A more detailed discussion of the ROP mechanisms is presented in Chapter 2.

In contrast to the polymerization of a large majority of unsaturated monomers, the ROP of cyclic monomers is often accompanied by the presence of a relatively high concentration of the unreacted monomer when the process comes to equilibrium. This feature is related to a pronounced reversibility of the propagation step (i.e. relatively high $k_{\mathrm{d}}$ in comparison to $k_{\mathrm{p}}$; Equation 1.2 ). Thus, a value of the equilibrium monomer concentration $\left([\mathrm{M}]_{\mathrm{eq}}\right)$ is usually taken as a measure of the monomer thermodynamic polymerizability. The corresponding thermodynamic formalism was developed by Dainton and Ivin in 1948 [14, 15], and subsequently by Tobolsky and Eisenberg [16, 17].

The reaction of a monomer with initiating agents (Equation 1.3a) should lead to active species capable of adding new monomer molecules (Equation 1.3b); moreover, they should be added faster than they undergo any side reactions, such as termination (Equation 1.3c) or transfer to monomer (Equation 1.3d).

$$
\begin{aligned}
& \mathrm{I}+\bigodot_{\mathrm{M}} \stackrel{k_{\mathrm{i}}}{\longrightarrow} \mathrm{I}-\mathrm{m}^{*} \\
& \ldots-(\mathrm{m})_{\mathrm{n}} \mathrm{m}^{*}+\bigodot_{\mathrm{M}} \frac{k_{\mathrm{p}}}{k_{\mathrm{d}}} \ldots-(\mathrm{m})_{\mathrm{n}+1} \mathrm{~m} * \\
& \ldots-(\mathrm{m})_{n} \mathrm{~m}^{*}+\quad \mathrm{X} \stackrel{k_{\mathrm{t}}}{\longrightarrow} \ldots-(\mathrm{m})_{\mathrm{n}} \mathrm{m}-\mathrm{X} \\
& \ldots-(\mathrm{m})_{\mathrm{n}} \mathrm{m}^{*}+\mathrm{M}_{\mathrm{M}}^{k_{\mathrm{tr}}} \longrightarrow \ldots-(\mathrm{m})_{\mathrm{n}} \mathrm{m}+\mathrm{m}^{*}
\end{aligned}
$$

where I denotes the initiator molecule, $\mathrm{m} *$ is the active species, $\mathrm{X}$ is the terminating agent, and $k_{\mathrm{p}}, k_{\mathrm{d}}, k_{\mathrm{t}}, k_{\mathrm{tr}}$ are the rate constants of propagation, depropagation, termination and transfer, respectively.

For an idealized, living polymerization: $k_{\mathrm{t}}=0$ and $k_{\mathrm{tr}}=0$. A discovery of the anionic living polymerization of vinyl and diene monomers by Szwarc and coworkers opened a new chapter in macromolecular science [18-20]. ROP, being the subject of the present chapter, may also proceed as a living process. However, molar mass and end group control of the resultant polymer is only possible when $k_{\mathrm{i}} \geq k_{\mathrm{p}}$ (Equations 1.3a and 1.3b). 
As both the thermodymamics $[2,7,8,21-27]$ and kinetics $[1-4,6-8,10,12]$ of ROP have been reviewed extensively in the past, this chapter provides a concise description of only the most important and general phenomena.

\section{2}

\section{Thermodynamics of the Ring-Opening Polymerization}

\subsection{1}

\section{Equilibrium Monomer Concentration: Ceiling/Floor Temperatures}

The formal thermodynamic criterion of a given monomer polymerizability is related to a sign of the free enthalpy (called also Gibbs energy) of polymerization (cf. Equation 1.1):

$$
\Delta G_{\mathrm{p}}(\mathrm{xy})=\Delta H_{\mathrm{p}}(\mathrm{xy})-T \Delta S_{\mathrm{p}}(\mathrm{xy})
$$

where $\mathrm{x}$ and $\mathrm{y}$ denote monomer and polymer states, respectively [i.e.: $\mathrm{x}$ and/or $\mathrm{y}=1$ (liquid), g (gaseous), c (solid amorphous), $\mathrm{c}^{\prime}$ (solid crystalline), s (solution)], $\Delta H_{\mathrm{p}}(\mathrm{xy})$ and $\Delta S_{\mathrm{p}}(\mathrm{xy})$ are the corresponding enthalpy and entropy of polymerization, and $T$ is the absolute temperature.

In agreement with the general rules of the thermodynamics of chemical processes, only when $\Delta G_{\mathrm{p}}(\mathrm{xy})<0$ is polymerization possible. It must be stressed, however, that the $\Delta G_{p}(x y)$ values usually depend on the monomer and polymer states. Even in solution, polymerization $\Delta G_{\mathrm{p}}(\mathrm{xy})$ may depend on the solvent used (see Section 1.2.2.2). Further analysis, if not otherwise indicated, will be related to ROP carried out in solution or in the monomer/polymer melt and under the constant temperature and pressure.

The free enthalpy of polymerization $\left(\Delta G_{\mathrm{p}}\right)$ may be expressed as a sum of standard enthalpy of polymerization $\left(\Delta G_{\mathrm{p}}^{\circ}\right)$ and a term related to instantaneous monomer molecules and growing macromolecules concentrations:

$$
\Delta G_{\mathrm{p}}=\Delta G_{\mathrm{p}}^{\mathrm{o}}+R T \ln \frac{\left[\ldots-(\mathrm{m})_{\mathrm{i}+1} \mathrm{~m}^{*}\right]}{[\mathrm{M}]\left[\ldots-(\mathrm{m})_{\mathrm{i}} \mathrm{m}^{*}\right]}
$$

where $R$ denotes the gas constant.

Following Flory's assumption that the reactivity of an active center, located at a macromolecule of a sufficiently long macromolecular chain, does not depend on its polymerization degree $\left(D P_{\mathrm{i}}\right)$, and taking into account that $\Delta G_{\mathrm{p}}^{\circ}=\Delta H_{\mathrm{p}}^{\circ}-T \Delta S_{\mathrm{p}}^{\circ}$ (where $\Delta H_{\mathrm{p}}^{\circ}$ and $\Delta S_{\mathrm{p}}^{\circ}$ denote a standard polymerization enthalpy and entropy, respectively), we obtain:

$$
\Delta G_{\mathrm{p}}=\Delta H_{\mathrm{p}}^{\mathrm{o}}-T\left(\Delta S_{\mathrm{p}}^{\circ}+R \ln [\mathrm{M}]\right)
$$


At equilibrium $\left(\Delta G_{\mathrm{p}}=0\right)$ - that is, when polymerization is complete the monomer concentration $\left([\mathrm{M}]_{\mathrm{eq}}\right)$ assumes a value determined by standard polymerization parameters $\left(\Delta H_{\mathrm{p}}^{\circ}\right.$ and $\left.\Delta S_{\mathrm{p}}^{\circ}\right)$ and polymerization temperature (see e.g. Refs. [10, $14-17,21-26])$ :

$$
\begin{aligned}
& \ln [\mathrm{M}]_{\mathrm{eq}}=\Delta H_{\mathrm{p}}^{\circ} / R T-\Delta S_{\mathrm{p}}^{\circ} / R \\
& {[\mathrm{M}]_{\mathrm{eq}}=\exp \left(\Delta H_{\mathrm{p}}^{\circ} / R T-\Delta S_{\mathrm{p}}^{\circ} / R\right)}
\end{aligned}
$$

Depending on the starting monomer concentration $\left([\mathrm{M}]_{0}\right)$, or actually on the $\left([\mathrm{M}]_{0}-[\mathrm{M}]_{\mathrm{eq}}\right) / \Sigma\left[\ldots \mathrm{m}_{\mathrm{i}}^{*}\right]$ ratio, polymers of various number average polymerization degrees $\left(D P_{n}\right)$ may be formed. Thus, polymerization is possible only when $[\mathrm{M}]_{0}>[\mathrm{M}]_{\mathrm{eq}}$. For shorter, oligomeric chains (approximately $D P_{\mathrm{n}} \leq 20$ ) that do not conform to the Flory's assumption, in the expressions for $[\mathrm{M}]_{\mathrm{eq}}$ the value of $D P_{\mathrm{n}}$ has to be taken into account (see Appendix in Ref. [28]):

$$
\begin{aligned}
& \ln \left(\frac{D P_{n}}{D P_{n}-1}[\mathrm{M}]_{\mathrm{eq}}\right)=\frac{\Delta H_{\mathrm{p}}^{\mathrm{o}}}{R T}-\frac{\Delta S_{\mathrm{p}}^{\mathrm{o}}}{R} \\
& {[\mathrm{M}]_{\mathrm{eq}}=\frac{D P_{n}-1}{D P_{n}} \exp \left(\frac{\Delta H_{\mathrm{p}}^{\circ}}{R T}-\frac{\Delta S_{\mathrm{p}}^{\circ}}{R}\right)}
\end{aligned}
$$

Figure 1.1 shows an example of applying Equation 1.8a to a determination of the standard thermodynamic parameters in the ROP of 1,4-dioxane-2-one (DX) using the experimentally determined $[\mathrm{M}]_{\mathrm{eq}} \mathrm{S}$ at various temperatures.

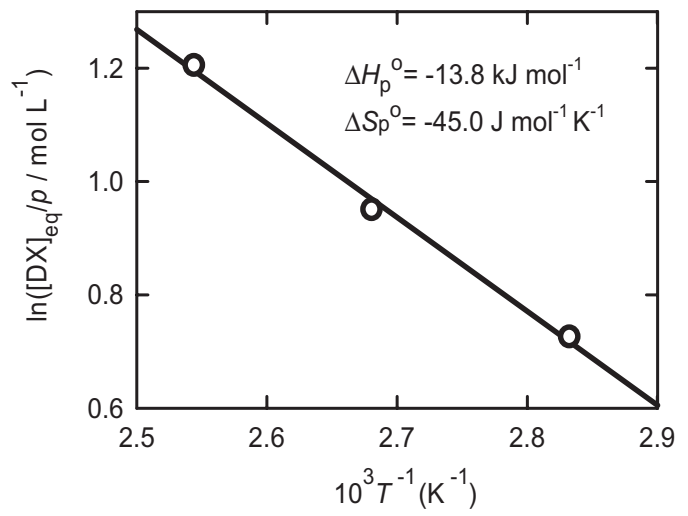

Figure 1.1 Plot of $\ln \left([D X]_{\mathrm{eq}} / p\right)$ (where $\left.p=\left(D P_{\mathrm{n}}-1\right) / D P_{\mathrm{n}}\right)$ on the reciprocal of the absolute temperature (Equation 1.8a). Bulk oligomerization of 1,4-dioxane-2-one (DX) initiated with the $n$-butyl alcohol/Sn(II) octoate mixture [28]. 
The slope and intercept of this dependence gives an access to $\Delta H_{\mathrm{p}}^{\circ}$ and $\Delta S_{\mathrm{p}}^{\circ}$ values, respectively [28]. Another typical method for determining $\Delta H_{\mathrm{p}}^{\circ}$ and $\Delta S_{\mathrm{p}}^{\circ}$ is based on the monomer and polymer combustion and specific heat measurements [29-36]. In turn, the thus-determined thermodynamic parameters allow an estimation to be made of the corresponding $[\mathrm{M}]_{\mathrm{eq}}$ values, this being especially useful when $[\mathrm{M}]_{\mathrm{eq}}$ is close to 0 .

Values of thermodynamic parameters characterizing the polymerization ability of the most important cyclic and heterocyclic monomers are compared in Table 1.1. Equation 1.6 indicates that, at standard conditions, monomers for which $\Delta H_{\mathrm{p}}^{\circ}<0$ and $\Delta S_{\mathrm{p}}^{\circ}>0$ can be polymerized at any temperature, whereas those with $\Delta H_{\mathrm{p}}^{\circ}>0$ and $\Delta S_{\mathrm{p}}^{\circ}<0$ cannot be converted into linear macromolecules. In the most typical case-that is, when $\Delta H_{\mathrm{p}}^{\circ}<0$ and $\Delta S_{\mathrm{p}}^{\circ}<0$-an increase in the polymerization temperature leads to an increase in $[\mathrm{M}]_{\mathrm{eq}}$ (Equation 1.7b). Eventually, at or above the so-called ceiling temperature $\left(T_{c}\right.$; Equation 1.9a), at which $[\mathrm{M}]_{\mathrm{eq}}=[\mathrm{M}]_{0}$, formation of the high polymer does not occur. In contrast, for $\Delta H_{\mathrm{p}}^{\circ}>0$ and $\Delta S_{\mathrm{p}}^{\circ}>0$, [M] $]_{\mathrm{eq}}$ decreases with increasing temperature (Equation 1.7b) and there is another critical temperature-called the floor temperature $\left(T_{\mathrm{f}}\right.$, Equation $\left.1.9 \mathrm{~b}\right)$, at or below which polymerization is thermodynamically forbidden.

$$
\begin{aligned}
& T_{\mathrm{c}}=\frac{\Delta H_{\mathrm{p}}^{\circ}}{\Delta S_{\mathrm{p}}^{\circ}+R \ln [\mathrm{M}]_{0}} ; \quad\left(\Delta H_{\mathrm{p}}^{\mathrm{o}}<0, \Delta S_{\mathrm{p}}^{\circ}<0\right) \\
& T_{\mathrm{f}}=\frac{\Delta H_{\mathrm{p}}^{\circ}}{\Delta S_{\mathrm{p}}^{\circ}+R \ln [\mathrm{M}]_{0}} ; \quad\left(\Delta H_{\mathrm{p}}^{\circ}>0, \Delta S_{\mathrm{p}}^{\circ}>0\right)
\end{aligned}
$$

For example, tetrahydrofuran (THF) cannot be polymerized above $T_{\mathrm{c}}=84^{\circ} \mathrm{C}$ [38], nor cyclo-octasulfur $\left(\mathrm{S}_{8}\right)$ below $T_{\mathrm{f}}=159^{\circ} \mathrm{C}[16,17]$. However, for the majority of monomers listed in Table 1.1, $T_{\mathrm{c}}$ and $T_{\mathrm{f}}$, for polymerization in the bulk, are well above or below the operable polymerization temperatures, respectively.

In general, the polymerization of cyclic monomers conforms to rules established for the hypothetical polymerization of cycloalkanes [15, 46]. The driving force for the polymerization of many cyclic compounds is their ring strain, which reflects the deviation from nondistorted bond angle values, bond stretching and/or compression, repulsion between eclipsed hydrogen atoms, and nonbonding interactions between substituents (angular, conformational and transannular strain, respectively). For systems in which the specific monomer-polymer-solvent interactions can be neglected, the enthalpy of polymerization may serve as a measure of the ring strain.

The polymerization of a majority of monomers is accompanied by an entropy decrease, due mostly to the loss in the translational degrees of freedom. In this situation, polymerization is thermodynamically allowed only when the enthalpic contribution into $\Delta G_{\mathrm{p}}$ prevails (thus, when $\Delta H_{\mathrm{p}}<0$ and $\Delta S_{\mathrm{p}}<0$, the inequality $\left|\Delta H_{\mathrm{p}}\right|>-T \Delta S_{\mathrm{p}}$ is required; cf. Equation 1.4). Therefore, the higher the ring strain, the lower the resulting monomer concentration at equilibrium (Equation 1.7b). 
Table 1.1 Standard thermodynamic parameters of polymerization of selected cyclic monomers.

\begin{tabular}{lllllll}
\hline Monomer & Ring size & xy & $\frac{\Delta{H_{\mathrm{p}}^{0}}^{a}}{\mathbf{k J m o l}^{-1}}$ & $\frac{\Delta \mathbf{S}_{\mathrm{p}}^{{ }^{a}}}{\mathrm{Jmol}^{-1} \mathbf{K}^{-1}}$ & $\frac{[\mathrm{M}]_{\mathrm{eq}}{ }^{b}}{\mathbf{m o l L}^{-1}}$ & Reference(s) \\
\hline $\mathrm{H}_{2} \mathrm{C}-\mathrm{CH}_{2}$ & 3 & $1 \mathrm{c}^{\prime}$ & $-113^{c}$ & $-69.1^{c}$ & $1.7 \times 10^{-15}$ & {$[15]$}
\end{tabular}

Cyclopropane<smiles>C1CO1</smiles>

Ethylene oxide<smiles>C1CCC1</smiles>

Cyclobutane<smiles>O=C1CCO1</smiles>

$\beta$-Propiolactone<smiles>C1CCCC1</smiles>

Cyclopentane<smiles>C1CCOC1</smiles>

5<smiles>O=C1CCCO1</smiles>

$\gamma$-Butyrolactone<smiles>C1CCSC1</smiles><smiles>COP1(=O)OCCO1</smiles>
SS

lc $-8^{c}$

$-85^{c}$

$1.2 \times 10^{3}$

[39]

Ethylene phosphate

$1 c^{\prime}$

$-82.3$

$-74$

$3 \times 10^{-11}$

$1 c^{\prime}$

$-21.2^{c}$

$-42.7^{c}$

$3.4 \times 10^{-1}$

Tetrahydrothiophene

$-13.5$

$1.62 \times 10^{-2}$

[40] 


\begin{tabular}{|c|c|c|c|c|c|c|}
\hline Monomer & Ring size & xy & $\frac{\Delta H_{\mathrm{p}}^{0^{a}}}{\mathrm{k} / \mathrm{mol}^{-1}}$ & $\frac{\Delta S_{\mathrm{p}}^{0^{a}}}{\mathrm{Jmol}^{-1} \mathrm{~K}^{-1}}$ & $\frac{[\mathrm{M}]_{\mathrm{eq}}{ }^{b}}{\mathrm{molL}^{-1}}$ & Reference(s) \\
\hline S & 5 & $1 c^{\prime}$ & 0.4 & -30.1 & $5.1 \times 10^{2}$ & {$[31]$} \\
\hline
\end{tabular}<smiles>C1CCCCC1</smiles>

Cyclohexane<smiles>O=C1CCCCO1</smiles>

$\delta$-Valerolactone<smiles>O=C1COCCO1</smiles>

1,4-Dioxane-2-one<smiles>C1OCOOO1</smiles>

Trimethylene carbonate<smiles>CC1CC(=O)C(C)C(=O)C1=O</smiles>

L,L-Lactide<smiles>O=[PH]1OCCCO1</smiles>

1,3-Propylene phosphite<smiles>O=C1CCCCN1</smiles>

6 


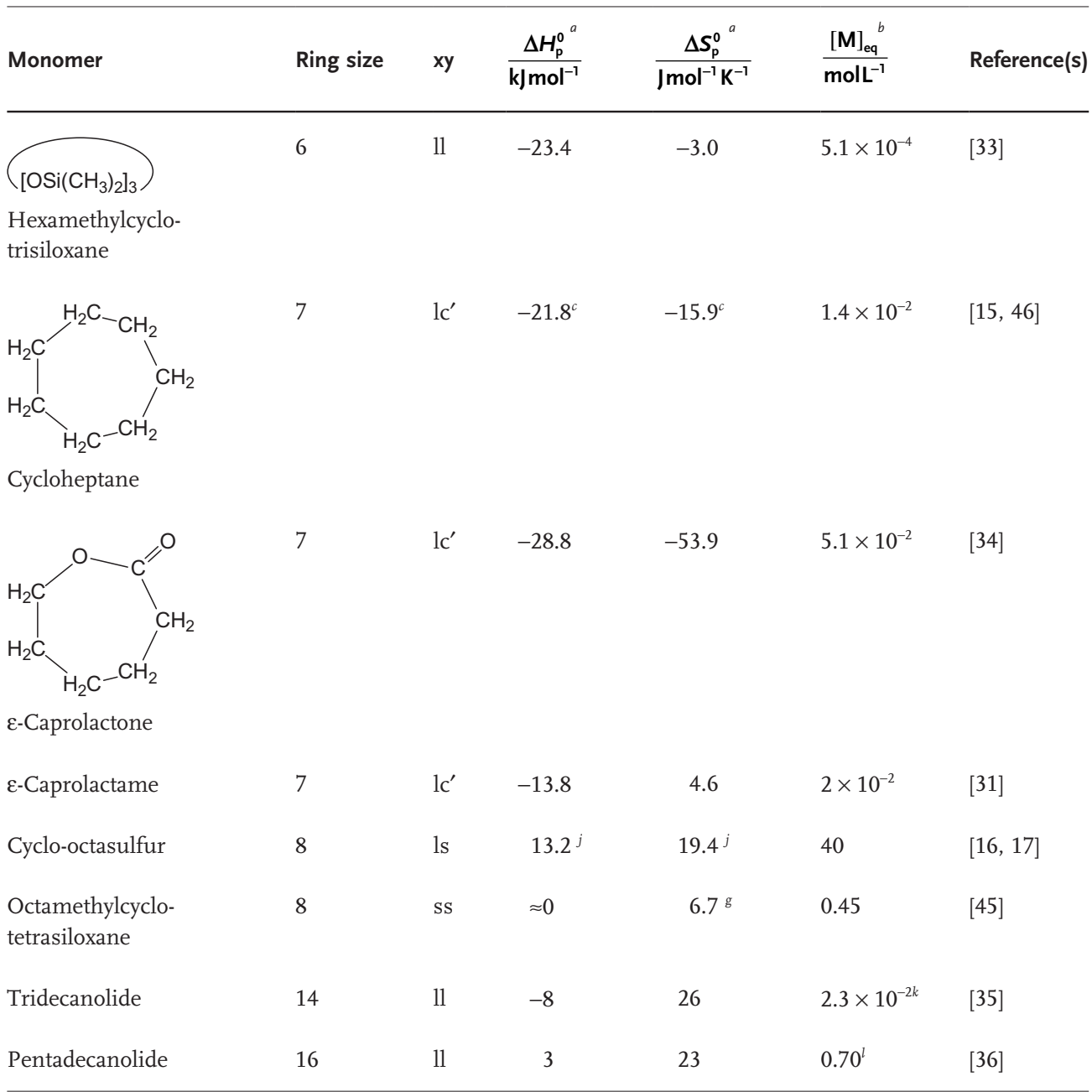

a At $298 \mathrm{~K}$ if not indicated otherwise.

b If not indicated otherwise calculated from Equation $1.7 \mathrm{~b}, \Delta H_{\mathrm{p}}$ and $\Delta S_{\mathrm{p}}^{\circ}$ determined thermochemically; standard state: weight fraction $=1$; concentrations recalculated from weight fractions to $\mathrm{moll}^{-1}$.

c $\Delta H_{\mathrm{p}}$ and $\Delta S_{\mathrm{p}}^{\circ}$ estimated by semi-empirical calculations.

d $\Delta H_{\mathrm{p}}$ and $\Delta S_{\mathrm{p}}^{\mathrm{o}}$ determined from the experimental $[\mathrm{M}]_{\mathrm{eq}}$ versus $\mathrm{T}^{-1}$ dependence in monomer/polymer melt, using Equation 1.7a; standard state: $1 \mathrm{moll}^{-1}$.

e $\Delta H_{\mathrm{p}}$ and $\Delta S_{\mathrm{p}}^{\mathrm{o}}$ determined from the experimental $[\mathrm{M}]_{\mathrm{eq}}$ versus $\mathrm{T}^{-1}$ dependence in monomer/polymer melt, using Equation 1.8a; standard state: $1 \mathrm{moll}^{-1}$.

f At $373 \mathrm{~K}$.

g $\Delta H_{\mathrm{p}}$ and $\Delta S_{\mathrm{p}}^{\circ}$ determined from the experimental $[\mathrm{M}]_{\mathrm{eq}}$ versus $\mathrm{T}^{-1}$ dependence in THF solution, using Equation 1.7a; standard state: $1 \mathrm{moll}^{-1}$.

h $\Delta H_{\mathrm{p}}$ and $\Delta S_{\mathrm{p}}^{\mathrm{o}}$ determined from the experimental $[\mathrm{M}]_{\mathrm{eq}}$ versus $\mathrm{T}^{-1}$ dependence in 1,4-dioxane solution, using Equation $1.7 \mathrm{a}$; standard state: $1 \mathrm{moll}^{-1}$.

i $\Delta H_{\mathrm{p}}$ and $\Delta S_{\mathrm{p}}^{\circ}$ determined from the experimental $[\mathrm{M}]_{\mathrm{eq}} \mathrm{vs} . \mathrm{T}^{-1}$ dependence in $\mathrm{CH}_{2} \mathrm{Cl}_{2}$ solution, using Equation 1.7a; standard state: $1 \mathrm{moll}^{-1}$.

j $\Delta H_{\mathrm{p}}$ and $\Delta S_{\mathrm{p}}^{\mathrm{o}}$ determined from the experimental $[\mathrm{M}]_{\mathrm{eq}}$ versus $\mathrm{T}^{-1}$ dependence in monomer/polymer melt, using Equation 1.7a; standard state: $1 \mathrm{~mol} \mathrm{~kg}^{-1}$; concentration recalculated from $\mathrm{mol} \mathrm{kg}^{-1}$ to $\mathrm{mol} \mathrm{l}^{-1}$.

k At $430 \mathrm{~K}$.

l At $370 \mathrm{~K}$. 
The angle and bond deformations are most pronounced for the three- and fourmembered rings, and this results in a high ring strain leading to negligible $[\mathrm{M}]_{\mathrm{eq}}$ values (Table 1.1). For example, the strain of a three-membered ring is so high that, although the formation of three-membered $\alpha$-lactone intermediates was postulated on the basis of quantum mechanical calculations [47], the cyclic ester has never been isolated.

The five- and six-membered cycles are the least strained, and some of these are ultimately unable to undergo polymerization. The ring strain for these monomers is derived mostly from the gauche interactions between $\mathrm{C}-\mathrm{H}$ bonds in the neighboring $\mathrm{CH}_{2}$ groups, or between $\mathrm{C}-\mathrm{H}$ bonds and the lone electron pairs at the endocyclic oxygen atom. Eventually, cyclopentane and THF show only moderate enthalpies of polymerization that lead to the relatively high $[\mathrm{M}]_{\mathrm{eq}} \mathrm{s}$. However, the introduction of a sulfur atom or a carbonyl group into the five-membered ring makes the resultant compounds incapable of high polymer formation under normal conditions. This is caused either by an increase in the atomic radius of the $\mathrm{S}$ heteroatom, or by a decrease in the number of bond oppositions, due to $\mathrm{sp}^{2}$ hybridization of the carbon atom in the $>\mathrm{C}=\mathrm{O}$ group. The six-membered alkanes and ethers assume the most convenient chair conformation in which the energy of the conformational interactions is negligible and the hypothetical $[\mathrm{M}]_{\mathrm{eq}}$ is well above any possible $[\mathrm{M}]_{0}$ values. In contrast, the presence of ester or siloxane moieties in the six-membered ring increases the strain in such a way that $\delta$ valerolactone, DX, lactides (LA), cyclic carbonates and hexamethylcyclotrisiloxane $\left(D_{3}\right)$ can be readily polymerized. The carbonyl group introduces a certain measure of strain into six-membered rings due to the flat geometry of the ester moiety $\left(-\mathrm{CH}_{2}-\mathrm{C}(=\mathrm{O})-\mathrm{O}-\right)$. Also, in the almost flat $\mathrm{D}_{3}$ molecule the $-\mathrm{Si}-\mathrm{O}-\mathrm{Si}-$ and $-\mathrm{O}-\mathrm{Si}-\mathrm{O}-$ bond angle distortions provide considerable polymerization enthalpy.

The thermodynamic data in Table 1.1, characterizing larger cyclic monomers, suggest that an increase in ring size leads to rather small ring strain (if any) and in turn to an increase in the polymerization entropy. The latter effect is due to a relatively high flexibility of the long polymethylene, polysulfur and polysiloxane sequences in the resultant polymer chain. Thus, for this group of monomers polymerization becomes entropy-driven. However, as mentioned earlier, the formation of a high polymer from cyclo-octasulfur is possible only above $T_{\mathrm{f}}=159^{\circ} \mathrm{C}$, whereas the polymerization of octamethylcyclotetrasiloxane and macrolides can proceed both at ambient and elevated temperatures.

Figure 1.2 illustrates the characteristic changes in standard thermodynamic parameters with increasing size of cyclic monomer, as shown by the example of lactones bulk polymerization. Similar dependencies were also observed for other monomers, though with only slight changes in the position of the local minima or maxima on the thermodynamic parameter-ring size dependencies [21, 22, 26].

Similar rules are also valid for the ring-opening metathesis polymerization (ROMP) of cyclic olefins [10, 13, 48, 49]. We refrain here from more providing a detailed analysis of this group of monomers; rather, it is sufficient to repeat an opinion expressed recently by Grubbs that “... the most favorable conditions for a 


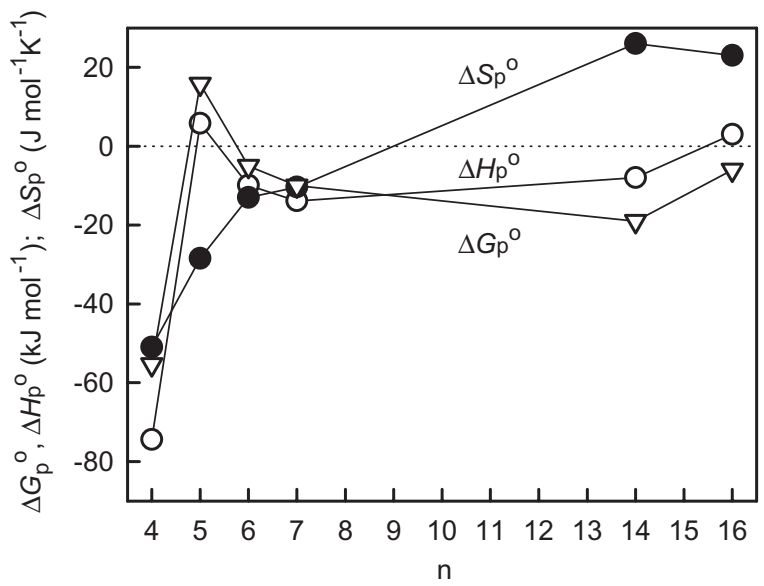

Figure 1.2 The dependencies of standard Gibbs energy $\left(\Delta G_{p}^{\circ}\right.$; $\nabla)$, enthalpy $\left(\Delta H_{p}^{\circ} ; O\right)$ and entropy $\left(\Delta S_{p}^{\circ} ; \bullet\right)$ of lactones polymerization on their ring sizes $(n)$. The temperature was dependent on the lactone, and ranged from 350 to $430 \mathrm{~K}$, monomer and polymer liquid. Data taken from Refs $[29,30$, 32, 34-36].

successful ROMP reaction is to use the highest monomer concentration at the lowest temperature possible" [13].

It is also worth remembering that, in contrast to the cyclic monomers, the large majority of unsaturated compounds polymerize, leaving a relatively low monomer concentration at the point of equilibrium. Indeed, when considering the nonsolvent, bulk polymerization of monomers such as ethylene, methyl acrylate or styrene, then at $25^{\circ} \mathrm{C}$ the situation is that $[\mathrm{M}]_{\mathrm{eq}}: \approx 10^{-10}, 10^{-9}$ or $10^{-6} \mathrm{moll}^{-1}$, respectively. When unsaturated monomers providing steric hindrance in the polymer units are considered, then homopolymerization may be hampered; here, 1,1diphenylethylene is the best example, as the joining of two consecutive units is prohibited. The introduction of a second (even small) substituent causes a considerable increase in $[\mathrm{M}]_{\mathrm{eq}}$. For example, in the case of methyl methacrylate or $\alpha$ methylstyrene, $[\mathrm{M}]_{\mathrm{eq}}=10^{-3}$ or $2.2 \mathrm{moll}^{-1}$ at $25^{\circ} \mathrm{C}$, respectively, have been determined $[50,51]$.

Finally, it must be stressed that the analysis of a given polymerization process, based on values of the corresponding thermodynamic parameters available in the literature, should be approached with some degree of caution. First, $\Delta H_{\mathrm{p}}^{\circ}$ and $\Delta S_{\mathrm{p}}^{\circ}$ depend substantially on the monomer and polymer states. For example, thermochemical measurements gave for 16-membered pentadecanolactone in the liquid phase $\Delta H_{\mathrm{p}}^{\circ}=3 \mathrm{kJmol}^{-1}$ and $\Delta S_{\mathrm{p}}^{\circ}=23 \mathrm{~J} \mathrm{~mol}^{-1} \mathrm{~K}^{-1}$, whereas in the crystalline phase $\Delta H_{\mathrm{p}}^{\mathrm{o}}=-39 \mathrm{kJmol}^{-1}$ and $\Delta S_{\mathrm{p}}^{\mathrm{o}}=-86 \mathrm{Jmol}^{-1} \mathrm{~K}^{-1}$ [36]. The difference between these sets of parameters is caused by corresponding phase transitions (crystallization/ melting) enthalpies and entropies, although for the melt or solution polymerization analysis the liquid-phase parameters are most likely correct. $\Delta S_{\mathrm{p}}^{\mathrm{o}}$ determined 
at different standard states (e.g. $1 \mathrm{moll}^{-1}$ and weight fraction $=1$ ) cannot be compared directly, and so must be recalculated. For example:

$$
\Delta S_{\mathrm{p}}^{\mathrm{o}}\left(\mathrm{mol} \mathrm{L}^{-1}\right)=\Delta S_{\mathrm{p}}^{\mathrm{o}}(\text { wt. fraction })+R \ln \frac{\mathrm{x} / \text { wt.fraction }}{1 / \mathrm{mol} \mathrm{L}^{-1}}
$$

where $\mathrm{x}$ denotes a weight fraction corresponding to $1 \mathrm{moll}^{-1}$ for a given monomer.

Moreover, Equation 1.9 show that the values of critical temperatures depend directly on the starting monomer concentration. Fortunately, the values for bulk monomer or for $1 \mathrm{moll}^{-1}$ are almost exclusively reported.

\section{2 .2}

\section{Selected Particular Cases}

The discussion of the thermodynamic prerequisites necessary for predicting given monomer polymerizability, as presented in Section 1.2.1, was based on the following assumptions:

- Polymerization is carried out in the homogeneous medium (e.g. monomer/ polymer melt or monomer/polymer/solvent solution).

- Monomer-polymer-solvent interactions can be neglected.

- A high molar mass polymer is exclusively formed.

Deviations from these assumptions lead, in certain polymerization systems, to interesting phenomena, an instructive example of which is provided by the solid-state 1,3,5-trioxane polymerization reviewed extensively in Ref. [3b], Section 7.3. Some other pertinent examples are briefly discussed below.

\subsubsection{Polymerization in Heterogeneous Systems}

The polymerization of industrially important monomers, such as DX or LA, is usually carried out above the melting temperature of their polymers in an homogeneous melt. Under these conditions [i.e. $>110^{\circ} \mathrm{C}$ for poly(DX) and $180^{\circ} \mathrm{C}$ for poly(LA)], the equilibrium monomer concentrations are relatively high-namely, $[\mathrm{DX}]_{\mathrm{eq}}>2.5 \mathrm{moll}^{-1}$ and $[\mathrm{LA}]_{\mathrm{eq}}>0.32 \mathrm{moll}^{-1}$, due to the moderate ring strain of the six-membered monomers. However, the molar fraction of the unreacted monomers can be reduced by aging the living polymerization mixtures below the melting temperature of the polyesters formed. Under these modified conditions, poly(DX) or poly(LA) crystallize, while the volume of the liquid phase (in which the unreacted monomer remains) decreases simultaneously. Subsequently, $[\mathrm{M}]$ increases temporarily above $[\mathrm{M}]_{\mathrm{eq}}$, after which an additional polymerization of the monomer proceeds, leading to an apparent decrease in $[\mathrm{M}]_{\text {eq }}$ (actually the molar fraction of $\mathrm{M}$ ). The eventual result is an almost complete consumption of the monomer. This result is achieved despite the conclusions that may be drawn from the values of thermodynamic parameters provided in Table 1.1 for both of the monomers under discussion [52, 53]. 


\subsubsection{Monomer-Polymer-Solvent Interactions}

For some cyclic monomers, such as six-membered propylene phosphite (PP) exerting a small ring strain, the energy of interaction between the monomer, polymer and solvent appears to be comparable with the ring strain energy. It has been shown that, for PP, $\Delta H_{\mathrm{p}}^{\circ}$ and $\Delta S_{\mathrm{p}}^{\circ}$ can change their signs when the conditions of polymerization are changed from polymerization in a monomer/polymer melt to that in methylene chloride, and vice versa (Table 1.1) [43, 44].

Ivin and Leonard, starting from Flory-Huggins theory [54], derived an equation relating the volume fractions of monomer, polymer and solvent $\left(\Phi_{\mathrm{m}}, \Phi_{\mathrm{p}}\right.$ and $\left.\Phi_{\mathrm{s}}\right)$, the monomer-solvent, polymer-solvent and monomer-polymer interaction parameters $\left(\chi_{\mathrm{ms}}, \chi_{\mathrm{ps}}\right.$ and $\left.\chi_{\mathrm{mp}}\right)$ with the absolute (i.e. independent of the polymerization conditions) thermodynamic parameters [55]:

$$
\Delta H_{\mathrm{p}}^{\mathrm{o}} / R T-\Delta S_{\mathrm{p}}^{\mathrm{o}} / R=\ln \Phi_{\mathrm{m}}+1+\left(\chi_{\mathrm{ms}}-\chi_{\mathrm{ps}}\left(\frac{V_{\mathrm{m}}}{V_{s}}\right)\right) \Phi_{s}+\chi_{\mathrm{mp}}\left(\Phi_{\mathrm{p}}-\Phi_{\mathrm{m}}\right)
$$

where $V_{\mathrm{m}}$ and $V_{\mathrm{s}}$ denote the molar volumes of monomer and solvent.

Equation 1.11 applied for correlation of the experimental data: $[\mathrm{PP}]_{\mathrm{eq}}$-temperature (for both bulk and solvent process) allowed, eventually, an estimation to be made of the absolute thermodynamic parameters of polymerization: $\Delta H_{\mathrm{p}}^{\circ}=-0.64 \mathrm{~kJ} \mathrm{~mol}^{-1}$ and $\Delta S_{\mathrm{p}}^{\mathrm{o}}=-5.8 \mathrm{~J} \mathrm{~mol}^{-1} \mathrm{~K}^{-1}$ (cf. the apparent parameters in Table 1.1) [44].

The specific monomer-solvent interaction plays also an important role in the cationic ROP of THF, as it exerts a considerable influence on the dependency of $[\mathrm{THF}]_{\mathrm{eq}}$ on $[\mathrm{THF}]_{0}[56]$. The observed phenomenon was explained by taking into account the higher nucleophilicity of THF monomer than that of the poly(THF) repeating units. Consequently, it was assumed that the stronger interaction between THF and solvent was only partially compensated by the comparatively weaker solvent-poly(THF) interactions. For a given $[\mathrm{THF}]_{0}$, $[\mathrm{THF}]_{\mathrm{eq}}$ was seen to increase in the following order: $\mathrm{CCl}_{4}<\mathrm{C}_{6} \mathrm{H}_{6}<\mathrm{CH}_{2} \mathrm{Cl}_{2}<\mathrm{CH}_{3} \mathrm{NO}_{2}$-that is, in the direction of the strongest monomer-solvent interactions. For instance, $[\mathrm{THF}]_{\mathrm{eq}}$ equal to $4.0,4.3,5.6$ and $6.0 \mathrm{moll}^{-1}$, respectively, were determined for $[\mathrm{THF}]_{0}=6 \mathrm{moll}^{-1}$ at $25^{\circ} \mathrm{C}[56]$. As might be expected, both $\Delta H_{\mathrm{p}}^{\circ}$ and $\Delta S_{\mathrm{p}}^{\mathrm{o}}$ were increased slightly in this order.

\subsubsection{Thermodynamics of Oligomerization}

It is well known that, for shorter chains (approximately up to $D P_{n}=20$ ), the position of the cyclic monomer-linear chain depends on its degree of polymerization:

$$
\begin{aligned}
& \mathrm{I}+\bigodot_{\mathrm{M}} \stackrel{K_{i}\left(K_{\mathrm{p} 0}\right)}{\rightleftharpoons} \mathrm{I}-\mathrm{m} * \\
& \mathrm{I}-\mathrm{m} *+\bigodot_{\mathrm{M}} \stackrel{K_{\mathrm{p} 1}}{\rightleftharpoons} \mathrm{I}-\mathrm{mm}^{*}
\end{aligned}
$$




$$
\begin{aligned}
& \mathrm{I}-\mathrm{mm} *+\bigodot_{\mathrm{M}} \stackrel{K_{\mathrm{p} 2}}{\rightleftharpoons} \mathrm{I}-\mathrm{mmm}^{*} \\
& \mathrm{I}-(\mathrm{m})_{\mathrm{i}-\mathrm{I}} \mathrm{m} *+\bigodot_{\mathrm{M}} \stackrel{K_{\mathrm{pi}}}{\rightleftharpoons}=\mathrm{I}-(\mathrm{m})_{\mathrm{i}} \mathrm{m} *
\end{aligned}
$$

The equilibrium constants for the first few monomer additions are not the same, as for an addition to a high polymer $\left(K_{\mathrm{p} 0} \neq K_{\mathrm{p} 1} \neq K_{\mathrm{p} 2} \neq \ldots K_{\mathrm{p} i}\right)$ due to an influence of the head- and tail-end-groups and usually $K_{\mathrm{p} 0}, K_{\mathrm{p} 1}, K_{\mathrm{p} 2} \ldots$ are larger than $K_{\mathrm{p} i}$. Thus, the Gibbs energy for the oligomerization process must be expressed as shown in Equation 1.5. Moreover, a higher equilibrium monomer concentration for the higher number average degree of oligomerization should be expected, as the corresponding equilibrium constants become smaller for longer chains:

$$
[\mathrm{M}]_{\mathrm{eq}}=\frac{\left[\mathrm{I}-(\mathrm{m})_{\mathrm{i}} \mathrm{m} *\right]}{K_{\mathrm{i}}\left[\mathrm{I}-(\mathrm{m})_{\mathrm{i}+1} \mathrm{~m} *\right]}
$$

Indeed, Heitz et al. studied the cationic oligomerization of THF in $\mathrm{CH}_{2} \mathrm{Cl}_{2}$ as solvent at $10^{\circ} \mathrm{C}$, using acetic anhydride as the transfer agent, and observed a gradual increase in $[\mathrm{THF}]_{\mathrm{eq}}$ from 1 to $4.3 \mathrm{moll}^{-1}$ for $D P_{\mathrm{n}}$ of poly(THF) increasing from 1 to 15 [57]. For $D P_{n} \geq 15$, the discussed dependence reached a plateau; thus, $[\mathrm{THF}]_{\mathrm{eq}}=4.3 \mathrm{moll}^{-1}$ was seen to be characteristic for the high polymer formation under the applied polymerization conditions ( $[\mathrm{THF}]_{0}=6 \mathrm{moll}^{-1}, \mathrm{CH}_{2} \mathrm{Cl}_{2}$ solvent, $10^{\circ} \mathrm{C}$ ). A rigorous treatment of the equilibrium oligomerization, leading alternatively to Equation 1.8a, and allowing determination of the standard thermodynamic parameters from the experimental $\ln [\mathrm{M}]_{\mathrm{eq}}$ versus $\mathrm{T}^{-1}$ dependence, is provided in Ref. [57].

More recently, the oligomerization of DX monomer in 1,4-dioxane as solvent and coinitiated with butyl alcohol $(\mathrm{BuOH})$, was studied using a variety of starting monomer concentrations at approximately constant $[\mathrm{DX}]_{0} /[\mathrm{BuOH}]_{0}$ ratios $[28]$. The resultant $[\mathrm{DX}]_{\mathrm{eq}}$ versus $[\mathrm{DX}]_{0}$ dependencies are shown in Figure 1.3.

Independent of temperature $\left(80,100\right.$ or $\left.120^{\circ} \mathrm{C}\right)$, [DX $]_{\mathrm{eq}}$ was seen to increase with increasing $[\mathrm{DX}]_{0}$ up to $[\mathrm{DX}]_{0} \approx 4 \mathrm{moll}^{-1}$, and then to level off at a constant value, independent of $[\mathrm{DX}]_{0}$. Again, the observed behavior could be explained by assuming an increase of $D P_{n}$ of the linear oligo(DX), this being in equilibrium with the DX monomer, for a higher $[\mathrm{DX}]_{0}$.

From the theory of polymerization thermodynamics, it can be deduced that in the vicinity of the ceiling $\left(T_{c}\right)$ and at higher temperatures, or in the vicinity of the floor $\left(T_{\mathrm{f}}\right)$ and at lower temperatures, no high molar mass polymer can be formed. Yet, the analysis provided above suggests that formation of shorter, oligomeric chains may be possible under these conditions. For example, $\gamma$-butyrolactone (BL) has a hypothetical equilibrium monomer concentration at $25^{\circ} \mathrm{C}$ which is equal to $3.3 \times 10^{3} \mathrm{moll}^{-1}$, which exceeds 250 -fold the BL concentration in bulk (Table 1.1); the hypothetical $T_{\mathrm{c}}$ is below $0 \mathrm{~K}$ (!), because $\Delta H_{\mathrm{p}}^{\circ}>0$ and $\Delta S_{\mathrm{p}}^{\circ}<0$ (Equation 1.9a) 


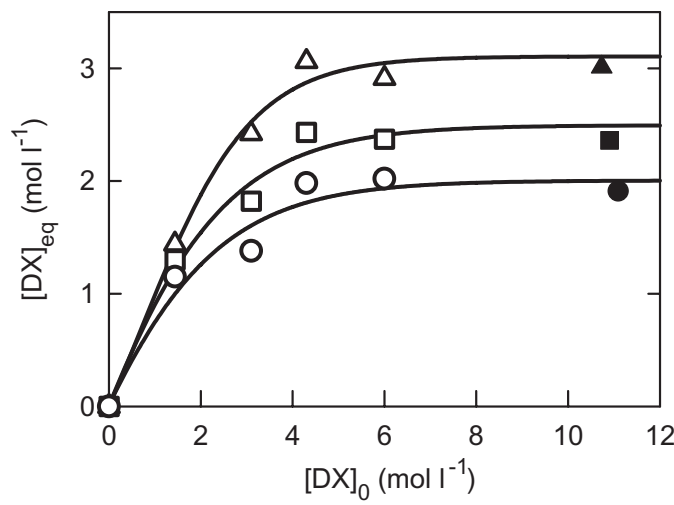

Figure 1.3 Plots of equilibrium monomer concentrations $\left([D X]_{\text {eq }}\right)$ on monomer concentration in the feed $\left([D X]_{0}\right)$ as obtained in a DX/tin octoate $\left(\mathrm{Sn}(\mathrm{Oct})_{2}\right) / \mathrm{BuOH}$ polymerization system. Conditions: $\left[\mathrm{Sn}(\mathrm{Oct})_{2}\right]_{0}=10^{-2} \mathrm{moll}^{-1}$. Open symbols indicate polymerization in 1,4-dioxane solvent; solid symbols indicate bulk polymerization. Temperatures (in ${ }^{\circ} \mathrm{C}$ ): $80(\mathrm{O}, \bullet)$, $100(\square, \mathbf{\square})$ and $120(\triangle, \boldsymbol{\Delta})$.

for this monomer. Consequently, BL is typically considered to be a monomer that is incapable of polymerizing [58], although it does not mean that BL cannot undergo ring-opening reactions at all. For most short chains the inequality takes place: $[\mathrm{BL}]\left[\mathrm{poly}(\mathrm{BL})_{\mathrm{i}}\right] \gg\left[\operatorname{poly}(\mathrm{BL})_{\mathrm{i}+1}\right]$, and the 'entropic term' may outweigh the $\Delta H_{\mathrm{i}}^{\circ} \geq 0$, making $\Delta G_{\mathrm{i}}<0$ (Equation 1.14); hence, shorter chains are allowed to be formed.

$$
\Delta G_{\mathrm{i}}=\Delta H_{\mathrm{i}}^{\mathrm{o}}-T \Delta S_{\mathrm{i}}^{\mathrm{o}}-R T \ln \frac{[\mathrm{BL}]\left[\operatorname{poly}(\mathrm{BL})_{\mathrm{i}}\right]}{\left[\operatorname{poly}(\mathrm{BL})_{\mathrm{i}+1}\right]}
$$

Indeed, some time ago it was reported that the ROP (actually oligomerization) of $\mathrm{BL}$ initiated with $\left\{\mathrm{Al}\left(\mathrm{O}^{i} \mathrm{Pr}\right)_{3}\right\}_{3}$ readily provided a series of poly(BL) chains:

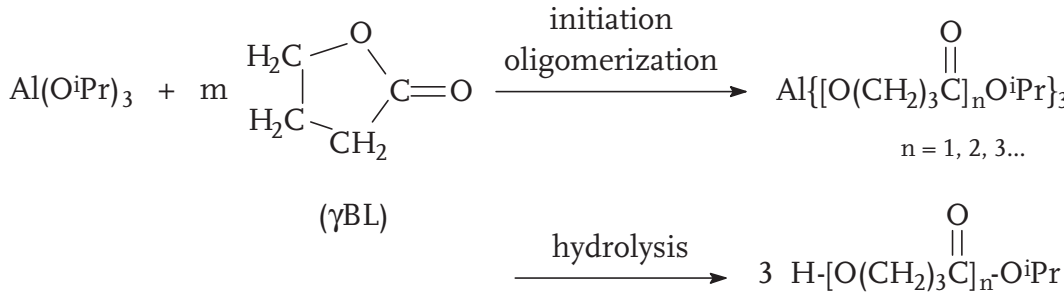

Mass spectrometric measurements revealed the formation of $i \mathrm{PrO}-(\mathrm{bl})_{\mathrm{n}}-\mathrm{H}$ oligomers with DP up to 10 [59-61] 
In addition, poly $(\mathrm{BL})$ of moderate molar mass $\left(M_{n}\right.$ up to $\left.3.5 \times 10^{3}\right)$ was prepared at high pressure $\left(2 \times 10^{4}\right.$ bar $)$ [62] in agreement with the $T_{c}$-pressure relationship as predicted by the Clausius-Clapeyron equation:

$$
\ln T_{\mathrm{c}}(p)=\ln T_{\mathrm{c}}(p=1 \text { bar })+\frac{V_{\mathrm{p}}-V_{\mathrm{m}}}{\Delta H_{\mathrm{p}}^{\circ}} p
$$

The term $V_{\mathrm{p}}-V_{\mathrm{m}}$ is typically negative since, in the majority of polymerizations, a molar volume contraction occurs of the reacting mixture. Under high pressure, liquid BL is transformed into crystalline poly(BL); in this case $\Delta H_{\mathrm{p}}^{\circ}=-6.8 \mathrm{kJmol}^{-1}$ has been determined [30]. Thus, $T_{\mathrm{c}}$ increases considerably under the high pressures that eventually allow poly(BL) to be prepared.

It is also worth noting that the ability to oligomerize, of the otherwise nonhomopolymerizable monomers, creates a possibility of copolymerization above or below their $T_{\mathrm{c}}$ or $T_{\mathrm{f}}$, respectively. These instructive examples are derived from the coordination copolymerization of BL with $\varepsilon$-caprolactone (CL) $[59,63,64]$ and the anionic copolymerization of $\mathrm{S}_{8}$ with three-membered alkylene sulfides (thiiranes) $[65,66]$, both of which produce high-molar mass copolymers (for further details, see Section 1.2.4).

\section{2 .3}

\section{Thermodynamics of Macrocyclization}

In ROP, the polymer repeating units usually contain the same reactive groups as those present in monomer, and which are responsible for propagation. Consequently, apart from propagation, a variety of reactions of chain transfer to the macromolecule with chain rupture can take place (Scheme 1.1). These side reactions-either unimolecular and/or bimolecular-lead unavoidably to the formation of macrocyclic molecules and/or to the segmental exchange (scrambling) of macromolecules. The consequence of the latter reaction is merely a broadening of the molar mass distribution of the polymer formed. Macrocyclization and segmental exchange reactions have been observed in the polymerization of various cyclic monomers, including alkenes [67], ethers [68], acetals [69], esters [70], amides [71], siloxanes [72] and sulfides [73]. Because of the potentially serious consequences of the macrocyclization limiting possibility of the controlled polymer synthesis, the thermodynamics of this process has undergone extensive study and review in the past (e.g. see Refs [3b, 22, 26, 74]).

Cyclic oligomers can be formed in two types of reaction: end-to-end closure and back-biting. The latter reaction proceeds via either a nucleophilic attack of the active species on its own macromolecular chain (anionic and coordination processes), or by a nucleophilic attack of the repeat unit (cationic process) on the active species in the same macromolecule (Scheme 1.1).

In the case of back-biting and a high molar mass of the linear polymer fraction, the expression for the corresponding equilibrium constant reads: 
(a) Propagation

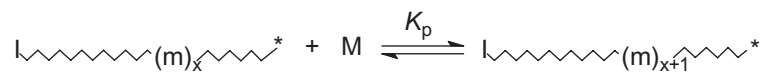

(b) Macrocyclization

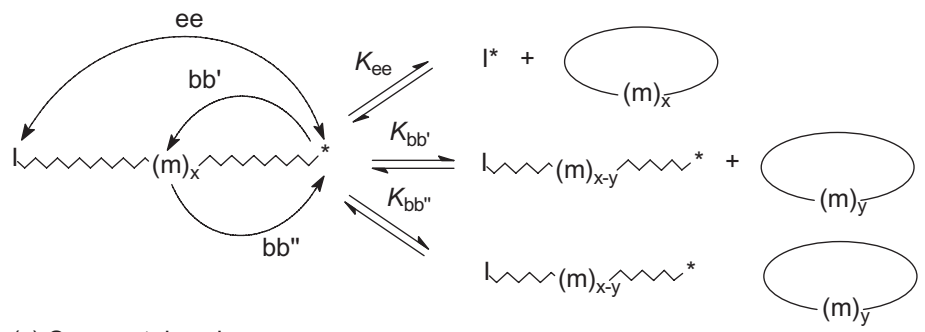

(c) Segmental exchange

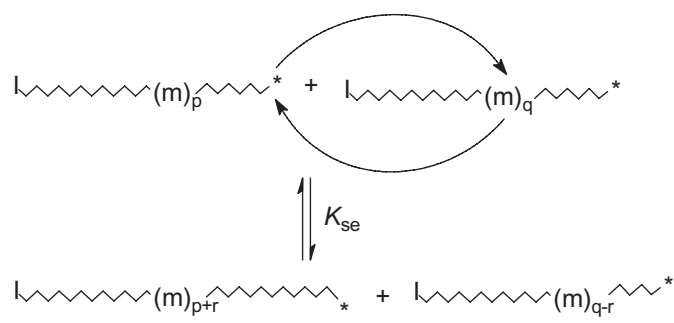

$K_{\mathrm{p}}=$ equilibrium constant of propagation; $K_{\mathrm{ee}}=$ equilibrium constant of end-to-end cycylization $K_{\mathrm{bb}}, K_{\mathrm{bb}}=$ equilibrium constants of back-biting; $K_{\mathrm{se}}=$ equilibrium constant of segmental exchange

Scheme 1.1 General scheme of ring-opening polymerization accompanied by chain transfer to macromolecule with chain rupture.

$$
K_{\mathrm{bb}}(\gamma)=\frac{\left[\ldots-\mathrm{m}_{\mathrm{x}}-\ldots\right][\mathrm{M}(\gamma)]_{\mathrm{eq}}}{\left[\ldots-\mathrm{m}_{\mathrm{x}-\mathrm{y}}-\ldots\right]} \approx[\mathrm{M}(\gamma)]_{\mathrm{eq}}
$$

where $\mathrm{M}(\gamma)$ represents the macrocycle containing $\gamma$ repeating units of ...-m-....

Theoretical considerations based on the Jacobson-Stockmayer theory [75, 76] led to the conclusion that, for nonstrained cycles in $\theta$ solvent:

$$
[\mathrm{M}(\gamma)]_{\mathrm{eq}} \sim \gamma^{-5 / 2}
$$

Thus, the equilibrium concentration of a given macrocycle should decrease monotonically with increasing ring size. Detailed studies of the equilibrium distribution of cyclic siloxane oligomers provided a very good agreement between the theoretical and experimental values for $y>25$; that is, for this range of cyclopolysiloxane sizes the plot of $\ln [\mathrm{M}(\gamma)]_{\mathrm{eq}}$ versus $\ln \gamma$ was a straight line with a slope of $-5 / 2$ [76]. Some deviation from the theoretical slope observed for $y>40$ was 
ascribed to the excluded volume effect [77, 78]. Careful studies of the anionic polymerization of CL revealed that, in the macrocycle sizes from $\gamma=3$ to 7 , the slope of $\ln [\mathrm{M}(\gamma)]_{\text {eq }}$ versus $\ln \gamma$ dependence was slightly lower than the theoretical counterpart, and equaled -2.2 [79]. Such deviation has been attributed to a screening of the given ester group from the active center by other atoms of its own cyclic molecule (i.e. to conformational hindrance).

In agreement with expectation, the concentration of nonstrained cycles-in line with Jacobson-Stockmayer theory-should be temperature-independent. The results of measurements performed by Ito and Yamashita [80] have shown that the concentration of cyclic CL oligomers changed very little in the temperature range from -78 to $50^{\circ} \mathrm{C}$. This observation led to the conclusion that $\Delta H_{\mathrm{p}}(\mathrm{i}) \approx 0$ (where $i \geq 2$ ). Likewise, for other polymerizing systems in which ring-chain equilibria take place, it is generally accepted that the propagation (or depropagation) of larger cyclics is accompanied by enthalpy changes that are equal to zero [76].

One important factor from a practical point of view is the critical concentration of the macrocycles (i.e. $\Sigma y[M(\gamma)]_{\text {eq }}$ ), the parameter which indicates the concentration of monomer which eventually will be converted into the macrocyclic fraction. For example, in CL and DX anionic and/or coordination polymerization, $\Sigma y[M(\gamma)]_{\mathrm{eq}}$ has been determined as being equal to $0.25 \mathrm{moll}^{-1}\left(25^{\circ} \mathrm{C}\right.$, THF) [79-81] and $0.95 \mathrm{moll}^{-1}$ (bulk, $100^{\circ} \mathrm{C}$ ) [28], respectively. Figure 1.4 shows a typical sizeexclusion chromatography (SEC) trace revealing the presence of a series of cyclic CL oligomers in the living, equilibrated polymerization mixture.

Cyclic oligomers are usually considered to be a contamination of the high polymers, as their presence results in a deterioration of the mechanical properties of

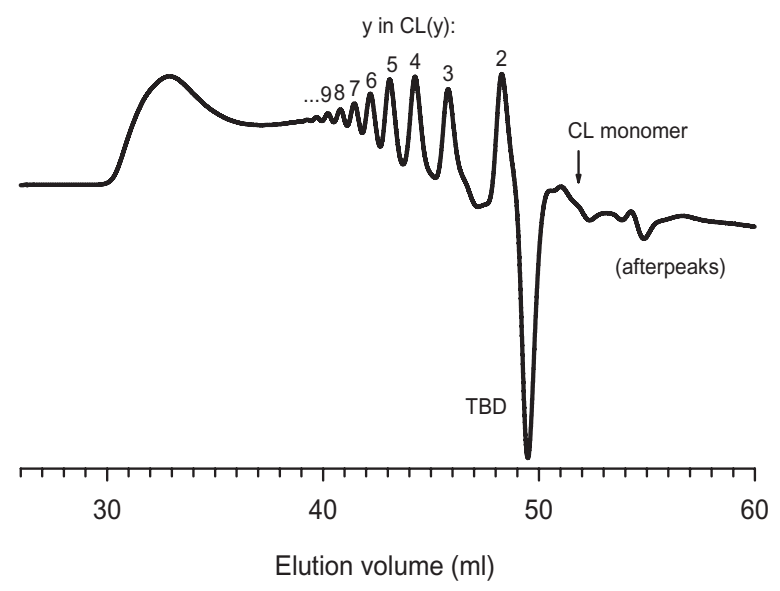

Figure 1.4 Size-exclusion chromatography of a living, equilibrated polymerization mixture: $\varepsilon$-caprolactone $(\mathrm{CL}) /$ triazabicyclodecene (TBD)/benzyl alcohol $(\mathrm{BzOH})$. Conditions: $[\mathrm{CL}]_{0}=0.5 \mathrm{moll}^{-1},[\mathrm{TBD}]_{0}=2 \times 10^{-2} \mathrm{moll}^{-1},[\mathrm{BzOH}]_{0}=2.5 \times 10^{-3}$ moll ${ }^{-1}$; THF solvent, $80^{\circ} \mathrm{C}$ (A. Duda and A. Kowalski, unpublished results). 
the final product. The formation of a cyclic fraction is especially undesirable when the synthesis of a functional polymer (e.g. oligodiols) is attempted, because cyclic macromolecules do not contain functional groups and cannot participate in chain extension reactions. Hence, it is interesting to note in this context, that two different phenomena can take place in ROP, namely kinetic enhancement in cyclics and kinetic enhancement in linear macromolecules. Thus, before the thermodynamic equilibrium in cyclics is reached-that is, during the kinetically controlled period - the concentration of either the cyclics or linear macromolecules may exceed those at thermodynamic equilibrium. The polymerization of ethylene oxide (EO) provides an instructive example. Here, the anionic process is practically devoid of macrocyclics formation, whereas the cationic process proceeds with significant amounts of cyclic oligomers that are formed in addition to the linear polymer. Thus, the final content of the cyclic dimer $(1,4-$ dioxane) may be as high as $90 \%$ [82]. The phenomena of kinetic depression or even elimination of the cyclic oligomers fraction are described in more detail in Section 1.3.2.3.

\subsection{4}

\section{Equilibrium Copolymerization}

The stoichiometric equation for copolymerization includes two or a higher number of comonomers:

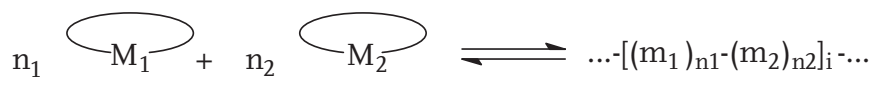

Similarly, as for homopolymerization, the difference in free enthalpy of the copolymer and comonomers $\left(\Delta G_{\mathrm{co}}\right)$ can be used as a formal criterion of a copolymerizability in the given comonomers system: that is, copolymerization is possible only when $\Delta G_{\mathrm{co}}<0$. It must be stressed, however, that for copolymerization $\Delta G_{\mathrm{co}}=0$ is a necessary (but not sufficient) condition in order for the thermodynamic equilibrium to take place. This is due to the higher degrees of freedom in the case of the copolymerization. Even when the partial equilibrium described by Equation 1.19 is established, the system can-in principle-spontaneously undergo an infinite number of reactions that lead to copolymers of different composition and/or microstructure [83]. In practice, the simplified, diad model of copolymerization is assumed; this consists of four reversible reactions where the structure of the repeating unit preceding the active center has no influence on the corresponding homo- and cross-propagation equilibria constants (Equation 1.20).

$$
\begin{aligned}
& \ldots-\mathrm{m}_{1}^{*}+\bigodot_{\mathrm{M}_{1}} \stackrel{K_{11}}{\rightleftharpoons} \ldots-\mathrm{m}_{1} \mathrm{~m}_{1} * \\
& \ldots-\mathrm{m}_{1} *+\bigodot_{\mathrm{M}_{2}} \stackrel{K_{12}}{\rightleftharpoons} \ldots-\mathrm{m}_{1} \mathrm{~m}_{2} *
\end{aligned}
$$




$$
\begin{aligned}
& \ldots-\mathrm{m}_{2}^{* *}+\bigodot_{\mathrm{M}_{1}} \stackrel{K_{21}}{\rightleftharpoons} \ldots-\mathrm{m}_{2} \mathrm{~m}_{1}^{*} \\
& \ldots-\mathrm{m}_{2}^{* *}+\bigodot_{\mathrm{M}_{2}} \stackrel{K_{22}}{\rightleftharpoons} \ldots-\mathrm{m}_{2} \mathrm{~m}_{2}{ }^{*}
\end{aligned}
$$

Since the interaction range between repeating units in polymer molecule is rather limited, the diad model operates satisfactorily for many copolymerization systems.

Starting from Equation 1.20, it can be easily shown that:

$$
\begin{gathered}
{\left[\mathrm{M}_{1}\right]_{\mathrm{eq}}=\frac{\left[\ldots-\mathrm{m}_{1} \mathrm{~m}_{1}^{*}\right]_{\mathrm{eq}}}{\left.K_{11}\left[\ldots-\mathrm{m}_{1}^{*}\right]\right]_{\mathrm{eq}}}} \\
\left(\frac{\left[\ldots-\mathrm{m}_{1} \mathrm{~m}_{1}^{*}\right]_{\mathrm{eq}}}{\left[\ldots-\mathrm{m}_{1}^{*}\right]_{\mathrm{eq}}}\right)_{\text {copo }} \approx\left(1+\frac{\left[\ldots-\mathrm{m}_{2} \mathrm{~m}_{1}^{*}\right]_{\mathrm{eq}}}{\left[\ldots-\mathrm{m}_{1} \mathrm{~m}_{1}^{*}\right]_{\mathrm{eq}}}\right)_{\text {copo }}^{-1}<\left(\frac{\left[\ldots-\mathrm{m}_{1} \mathrm{~m}_{1}^{*}\right]_{\mathrm{eq}}}{\left[\ldots-\mathrm{m}_{1}^{*}\right]_{\mathrm{eq}}}\right)_{\text {homo }} \approx 1
\end{gathered}
$$

which finally leads to the conclusion that $\left[\mathrm{M}_{1}\right]_{\text {eq,copo }}<\left[\mathrm{M}_{1}\right]_{\text {eq.homo }}$.

The equilibrium concentration of comonomer $\mathrm{M}_{1}\left(\right.$ or $\mathrm{M}_{2}$ ) in copolymerization is lower than that in homopolymerization because the cross-propagation reduces the concentration of the $\ldots-\mathrm{m}_{1} \mathrm{~m}_{1} *$ (or ...- $\mathrm{m}_{2} \mathrm{~m}_{2} *$ ) centers.

$\left[\mathrm{M}_{1}\right]_{\mathrm{eq}, \mathrm{copo}}$ can also be inter-related with an average block length derived from a given comonomer $\left(D P_{\mathrm{n}(\mathrm{M})}\right)$, e.g. for $\mathrm{M}_{1}$ :

$$
\left[\mathrm{M}_{1}\right]_{\mathrm{eq}}=\frac{1-D P_{\mathrm{n}(\mathrm{M} 1)}}{K_{11} D P_{\mathrm{n}(\mathrm{M} 1)}}
$$

Here, $D P_{\mathrm{n}(\mathrm{M} 1)}$ corresponds to the number average degree of oligomerization in Equation 1.13. Equation 1.22 allows the prediction to be made whether the copolymerization of a given comonomers pair is possible, even if both are nonhomopolymerizable (i.e. when $\left[\mathrm{M}_{1}\right]_{0}<1 / K_{11}$ and $\left[\mathrm{M}_{2}\right]_{0}<1 / K_{22}$ ). The necessary conditions are: $K_{12} K_{21}>K_{11} K_{22}$ and $\left[\mathrm{M}_{1}\right]_{0}\left[\mathrm{M}_{2}\right]_{0}>1 / K_{12} K_{21}$. Thus, the formation of heterodiads should be privileged.

Although a more rigorous and systematic treatment of the equilibrium copolymerization would be beyond the scope of this chapter, the interested reader is referred to an authoritative review [84] and recently reported research data [83, 85-88]. It is of interest to note here that some thermodynamic parameters can be obtained only by using the copolymerization studies approach. For example, in the case of the nonhomopolymerizable six-membered 1,3-dioxolane, parameters of $\left(\mathrm{M}_{1}\right) K_{111}=0.05 \mathrm{moll}^{-1}\left(\right.$ at $\left.0{ }^{\circ} \mathrm{C}\right), \Delta H_{\mathrm{p}}^{\circ}=-3 \mathrm{kJmol}^{-1}$, and $\Delta S_{\mathrm{p}}^{\circ}=-36 \mathrm{kJmol}^{-1}$ have been determined $[87 \mathrm{c}]$. 
The results of more recent studies have revealed that copolymerization of the nonhomopolymerizable BL with CL and other monomers provides high molar mass polymers [59, 63, 64]. For example:<smiles>[R1]C1CCC(=O)O1</smiles>

(BL)

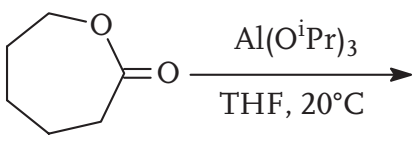

(CL)<smiles>CC[PH+](C)OC1(C)CC1CCCOC(C)(C)C(=O)CCCCCOC1(C)CC1(C)C</smiles>

The dependence of $\gamma$-butyroyl repeating unit (bl) content in the copolymer $\left(F_{\mathrm{bl}}\right)$, on the BL monomer content in the feed $\left(f_{\mathrm{BL}}\right)$ is shown in Figure 1.5. As might be expected from the copolymerization of a monomer which is unable to provide high polymers, even with a major excess of BL in the feed ([BL $]_{0} /[C L]_{0}$ equal to 11.9$)$, the -bl- content in the copolymer should not exceed $50 \mathrm{~mol} \%$. Thus, one could expect the formation of a close to alternating copolymer at a sufficiently large excess of BL. In fact, the ${ }^{13} \mathrm{C}$ NMR spectral analysis pointed towards a pseudoperiodic copolymer structure [59]. The BL/CL copolymer synthesis was successful, despite the fact that BL monomer addition to its own -bl* active chain ends was highly reversible, as the -bl* unit could be blocked via a practically irreversible CL addition. In addition, when BL is present in high excess over CL (i.e. [BL] > [CL]), then BL addition proceeds faster than that of CL.

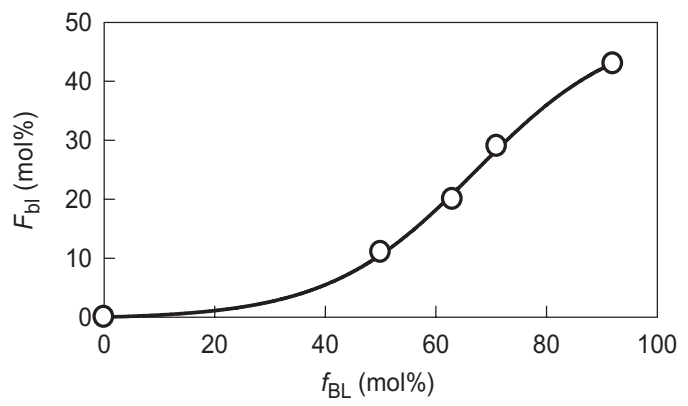

Figure 1.5 Dependence of $\gamma$-butyroyl (bl) units content in the $\gamma$-butyrolactone $(\mathrm{BL}) / \varepsilon$-caprolactone $(\mathrm{CL})$ copolymer $\left(F_{\mathrm{bl}}=100[\mathrm{bl}] /([\mathrm{bl}]+[\mathrm{cl}])\right)$, on the $\mathrm{BL}$ monomer content in the feed $\left(f_{\mathrm{BL}}=100[\mathrm{BL}]_{0} /\left([\mathrm{BL}]_{0}+[\mathrm{CL}]_{0}\right) \cdot \mathrm{cl}=\varepsilon\right.$-caproyl unit content [89]. 
Similarly, the earlier studies of $\mathrm{S}_{8}$ copolymerization with thiiranes (e.g. propylene sulfide; $\mathrm{PS}$ ), at temperatures below $T_{\mathrm{f}}$ for $\mathrm{S}_{8}$ homopolymerization, revealed that the average sulfur rank in the copolymer (i.e. average $x$ in $-\left[\mathrm{CH}_{2} \mathrm{CH}\left(\mathrm{CH}_{3}\right) \mathrm{S}_{x}\right]_{n}-$ ) was increased from 1 to 7 when the $8\left[\mathrm{~S}_{8}\right]_{0} /[\mathrm{PS}]_{0}$ ratio was increasing from 0 to 10 $[65,66]$.

The situation of a monomer incapable of producing high polymers above $T_{\mathrm{c}}$ or below $T_{\mathrm{f}}$ is similar to a that of monomer which cannot homopolymerize at a given temperature but is reaching its polymer-monomer equilibrium. Under these conditions, no further increase in monomer consumption takes place; however, the introduction at this moment of another monomer-which is able to homopolymerize-leads to the formation of a block copolymer with a bridge that follows the first homopolymer block and the build of the gradient copolymer. This was observed when LA was first brought to the polymer-monomer equilibrium, after which CL was introduced into the system [90].

\section{2 .5}

\section{Molar Mass Distribution in the Equilibrium Polymerization}

The living polymerization of strained three- and four-membered monomers typically provides polymers with a narrow molar mass distribution, best described by the Poisson function [91], for which the dispersity indexes $\left(D=D P_{\mathrm{w}} / D P_{\mathrm{n}}=M_{w} / M_{n}\right)$ assume values in the range $\sim 1.25 \geq D>1$, depending on the polymer chain length (Equation 1.24). As discussed earlier, the polymerization of these monomers is essentially irreversible.

$$
D=\frac{D P_{\mathrm{w}}}{D P_{\mathrm{n}}}=\frac{D P_{\mathrm{n}}}{\left(1+D P_{\mathrm{n}}\right)^{2}}
$$

For the larger ring sizes, both propagation and depropagation must be taken into account (Equation 1.3b), and a certain measurable concentration of the unreacted monomer appears when the system comes to thermodynamic equilibrium $\left([\mathrm{M}]_{\mathrm{eq}}=1 / K_{\mathrm{p}}=k_{\mathrm{d}} / k_{\mathrm{p}}\right)$. In this case, the molar mass distribution may be described by the most probable (Flory-Schultz) distribution function [92], for which:

$$
D=\frac{D P_{\mathrm{w}}}{D P_{\mathrm{n}}}=2-\frac{1}{D P_{\mathrm{n}}}
$$

Consequently, for the high molar mass polymer, $D=2$ should be expected, whereas even for monomers such as lactides having a relatively high $[\mathrm{LA}]_{\mathrm{eq}}$ at typical polymerization temperatures $\left(0.055 \mathrm{moll}^{-1}\right.$ at $80^{\circ} \mathrm{C}$ [42]), values of $D<1.15$ are often reported (see Ref. [93] and references cited therein).

The reason for such a situation occurring is related to the fact that the equilibria at which the polymerizations are stopped are in fact incomplete. Examples of numerically computed dependences of $D P_{\mathrm{w}} / D P_{\mathrm{n}}$ on monomer conversion, 


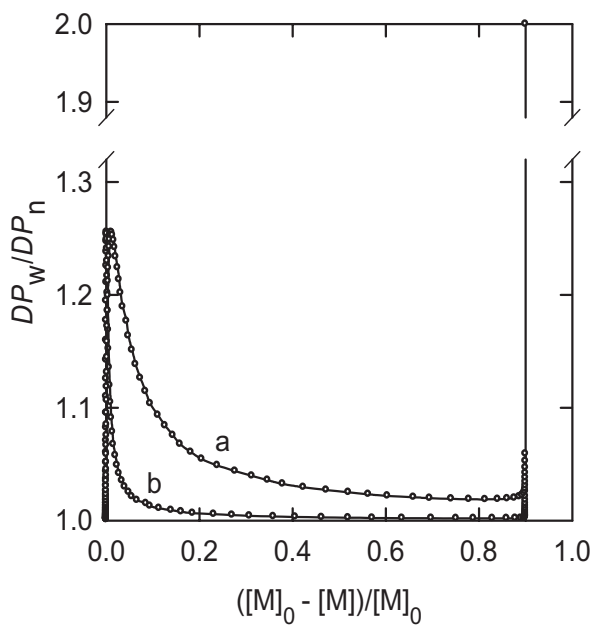

Figure 1.6 Computed dependence of dispersity index $\left(D P_{\mathrm{w}} / D P_{\mathrm{n}}\right)$ of the polymer formed by living polymerization with reversible propagation in relation to the degree of monomer conversion $\left(\left([\mathrm{M}]_{0}-[\mathrm{M}]_{\mathrm{eq}}\right) /[\mathrm{M}]_{0}\right)$. Assumptions: $[\mathrm{M}]_{0}=1.0 \mathrm{moll}^{-1} ;[\mathrm{l}]_{0}=10^{-2}$ (curve a), $0.10^{-3}$ (curve b) $\mathrm{moll}^{-1}$; $[\mathrm{M}]_{\mathrm{eq}}=0.1 \mathrm{moll}^{-1}[94]$.

resulting from depropagation, are shown in Figure 1.6 [94]. These reversible polymerizations can be living and, despite the remarkably high $[\mathrm{M}]_{\mathrm{eq}}$, a polymer with a $D$-value close to that resulting from a Poisson distribution can be obtained under kinetically controlled conditions, and even at high yield close to 'complete' monomer conversion. At this point it is worth noting that, to reach $D=1.99$ which is characteristic of an almost-complete equilibrium-it would take almost 100 -fold longer than would be necessary for a $99.9 \%$ monomer conversion (i.e. $\left.0.999\left([\mathrm{M}]_{0}-[\mathrm{M}]_{\mathrm{eq}}\right) /[\mathrm{M}]_{0}\right)$, under the assumed polymerization conditions [94].

Chain-transfer side reactions (see Scheme 1.1) can also cause substantial increases in $D$-values. Macrocyclization is particularly poor in this respect, leading to a complete equilibrium and an especially broad molar mass distribution (see e.g. Figure 1.4). On the other hand, a reversible polymerization devoid of macrocyclization, but accompanied by the segmental exchange reactions, can fulfill the criteria of the living process [95-99]. However, in this case the $D$-value also increases with conversion, reaching at equilibrium a value which is predicted by Equation 1.24 and characteristic of the most probable molar mass distribution. Figure 1.7 illustrates the dependence of $M_{w} / M_{n}$ determined for LA polymerization initiated with $\mathrm{Sn}(\mathrm{II})$ alkoxide [98].

It is remarkable that a $M_{w} / M_{\mathrm{n}}$ ratio of approximately $80 \%$ for LA conversion does not differ much from that expected for a Poisson distribution. Finally, the same system, when nearing the thermodynamically controlled region, the $M_{w} / M_{n}$ is approaching $\approx 2$. 


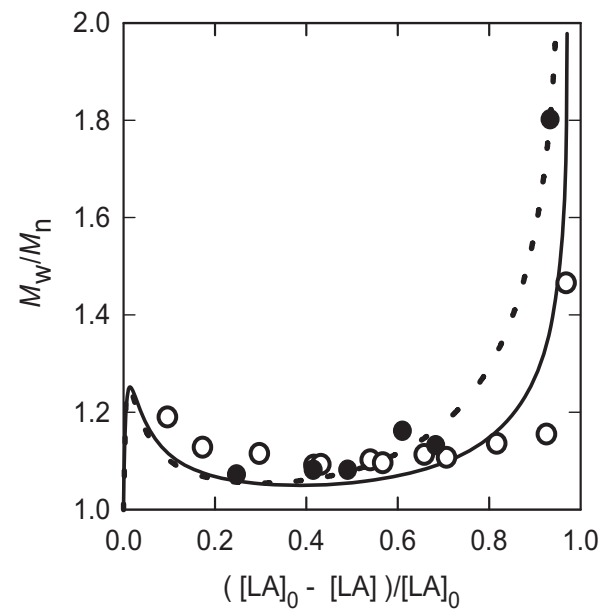

Figure 1.7 Dependence of dispersity indexes $\left(M_{w} / M_{n}\right)$ of poly (L-lactide) on the degree of (O). The points represent experimental data; the lines were computed from the kinetic monomer conversion. Conditions of scheme in which reversible propagation is polymerization: $[\mathrm{LA}]_{0}=1.0 \mathrm{moll}^{-1}$, $\mathrm{THF}$ accompanied by the segmental exchange solvent; $\left[\mathrm{Sn}(\mathrm{OBu})_{2}\right]_{0}\left(\right.$ in $\left.\mathrm{moll}^{-1}\right)=5 \times 10^{-3}(\bullet)$, reactions [Scheme 1.1, reactions (a) and (c)] $8.9 \times 10^{-3}(\mathrm{O})$; temperatures: $80^{\circ} \mathrm{C}(\bullet), 20^{\circ} \mathrm{C}$ [98].

\section{3}

\section{Kinetics of Ring-Opening Polymerization}

\subsection{1}

\section{Thermodynamic and Kinetic Polymerizability}

Polymerizability, in terms of the kinetics of propagation formalism, is related to a sign of the molar free enthalpy (Gibbs energy) of activation $\left(\Delta G_{\mathrm{p}}^{\neq}\right)$, this being a measure of the energy barrier in the elementary act of propagation (Equations 1.2 or 1.3b), for which $\Delta G_{\mathrm{p}}^{\neq}$assumes exclusively positive values. For example, when $\Delta G_{\mathrm{p}}^{\neq}<0$ this means that a given reaction is more complex and does not exclusively correspond to the elementary act of macromolecular chain growth. The resultant rate constant of propagation ( $k_{\mathrm{p}}$; see Equation 1.26 [100]) for a given mechanism and structure of active centers should assume values assuring operable polymerization times at a given temperature.

$$
k_{\mathrm{p}}=\frac{k_{\mathrm{b}} T}{h} \exp \left(-\frac{\Delta G_{\mathrm{p}}^{\neq}}{R T}\right)=\frac{k_{\mathrm{b}} T}{h} \exp \left(-\frac{\Delta H_{\mathrm{p}}^{\neq}}{R T}+\frac{\Delta S_{\mathrm{p}}^{\neq}}{R}\right)
$$

where $k_{\mathrm{b}}, h, \Delta H_{\mathrm{p}}^{\neq}, \Delta S_{\mathrm{p}}^{\neq}$denote the Boltzman constant, Planck constant, enthalpy and entropy of activation, respectively.

As highlighted in Section 1.1, the fulfillment of thermodynamic requirements is a necessary-but not sufficient-prerequisite for a polymerization to occur. A typical example is the polymerization of THF; here, although there is no anionic 


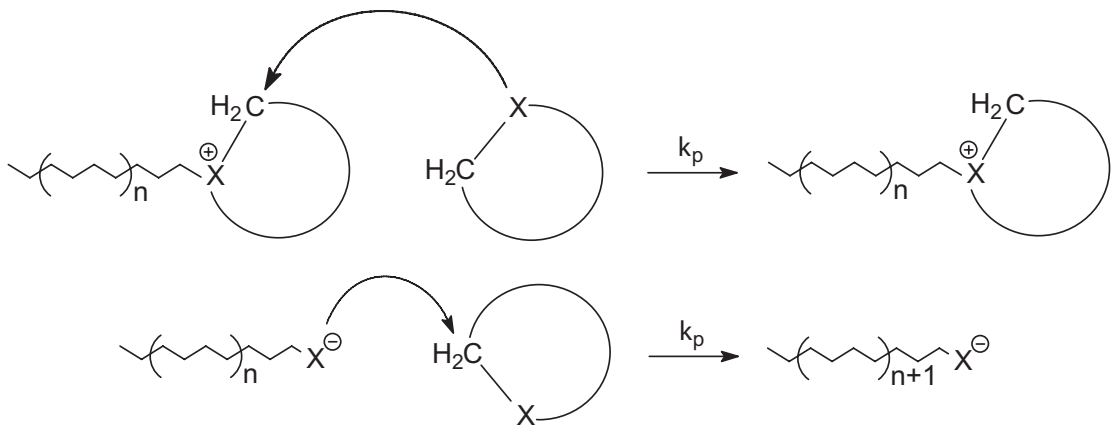

Scheme 1.2 Comparison of cationic and anionic propagation pathways in the ROP of heterocyclic monomers.

pathway, a cationic process provides poly(THF) readily, at least at temperatures below $T_{\mathrm{c}}$ [3]. In the cationic polymerization, ring opening proceeds with methylene carbon-heteroatom bond ( $-\mathrm{CH}_{2}-\mathrm{X}-$ ) cleavage in the 'activated' monomer as a fragment of the active center (onium ion), whilst the anionic propagation requires $-\mathrm{CH}_{2}-\mathrm{X}$ - bond splitting in the monomer per se (Scheme 1.2).

Thus, for the 'bare' monomer the high $\Delta G_{\mathrm{p}}^{\neq}$(or actually $\Delta H_{\mathrm{p}}^{\neq}$due to the high $-\mathrm{CH}_{2}-\mathrm{O}-$ bond strength), and therefore low $k_{\mathrm{p}}$, preclude anionic propagation. In contrast, for the much more strained EO monomer, both anionic and cationic ring opening will function equally well.

In general, 'thermodynamic polymerizability' cannot be taken as a direct measure of a monomer's reactivity. For example, the rate constants for the basic hydrolysis of BL and CL (under comparable conditions) are close to one another $\left(1.5 \times 10^{-4}\right.$ and $2.6 \times 10^{-4} \mathrm{~mol}^{-1} 1 \mathrm{~s}^{-1}$, respectively) [101], although the corresponding enthalpies of polymerization differ considerably (cf. Table 1.1). In connection with the latter observation it is worth noting that the calculated absolute ring strains of BL and CL are not very different [58]. Thus a difference between BL and CL polymerizabilities is related to the rate of the back, de-propagation reaction, being much more faster for BL monomer. For another pair of monomers, such as $\beta$ propiolactone (PL) and CL, the rate constants of propagation in the anionic process differ by about $10^{3}$-fold in favor of the less-strained CL [102].

More recently, the kinetics of polymerization of the 6-, 7-, 9-, 12-, 13-, 16 and 17-membered lactones, either initiated with a zinc 2-ethylhexanoate/butyl alcohol system [103] or catalyzed enzymatically [103, 104], have been studied. For the resultant zinc alkoxide-propagating species the following relative polymerization rates were measured: 2500, 330, 21, 0.9, 1, 0.9 and 1, respectively (bulk polymerization, $100^{\circ} \mathrm{C}$ ). As active species operating in the polymerization of various lactones in this system are structurally identical (viz. $-\mathrm{C}(\mathrm{O})\left(\mathrm{CH}_{2}\right)_{\mathrm{m}-1} \mathrm{CH}_{2} \mathrm{O}-\mathrm{Zn}-$ ), the order of the polymerization rates was seen to be equivalent to the order of lactone reactivities. A comparison of lactone ring size with relative polymerization rate showed that, the larger the lactone ring, the lower was its reactivity (reactivities of the 12-, 13-, 16- and 17-membered lactones were practically identical, allowing for experimental error). It might be expected that, in the transition state of propagation, lactone strain is partially released and the resultant $\Delta H_{\mathrm{p}}^{\neq}$is lower for strained 
monomers compared to non-strained monomers. This, most likely, is the main reason why the reactivity of lactones decreases with their increasing sizes and eventually reaches a constant value for larger rings. Other factors, such as the electrophilicity of the monomer acyl atom or steric hindrance, both of which hamper the approach of the active species to the lactone ester group, may also play a minor role.

Interestingly, the order of enzymatic polymerization rates showed an inverted dependence on ring size, namely: 0.10:0.13:0.19:0.74:1.0 for the 7-, 12-, 13-, 16and 17-membered lactones, respectively [103]. This kinetic behavior can be explained by assuming that, in enzymatic polymerization, the rate-determining step involves the formation of a lactone-enzyme complex. The latter reaction is promoted by the hydrophobicity of the lactone monomer, which is higher for the larger lactone rings. The conclusion reached was that, for the enzymatic process, the thermodynamic and kinetic polymerizabilities with regards to monomer ring size were in reverse sequence.

\subsection{2}

\section{Kinetics of Living Polymerization}

Living polymerization constitutes a particularly useful model system for conducting rigorous and systematic kinetic studies to determine the absolute rate constants of involved elementary reactions. As the kinetics of ROP has been reviewed on several occasions in the past [3a, 4, 7, 12, 23, 24, 105-107], we will at this point present only a brief summary of the most important phenomena, complemented with some recent findings.

The anionic polymerization of EO was, historically speaking, the first ROP to conform to the living polymerization criteria. As early as the 1940s, Flory had observed that the anionic propagation of EO could proceed without side reactions, such as irreversible transfer and termination [108, 109]. At the time, an analysis of this process presented by Flory pointed to the molar mass control given by the molar $\left([\mathrm{EO}]_{0}-[\mathrm{EO}]\right) /[\mathrm{I}]_{0}$ ratio and a Poisson molar mass distribution of the resultant poly(EO). Some 20 years later, however, living anionic polymerization of another class of cyclic monomer, the alkylene sulfides (thiiranes), was reported [110, 111]. This discovery was followed by an establishment of the living polymerization conditions for anionic and coordination (pseudoanionic) polymerizations of lactones of various ring sizes [81, 112-116], lactams (activated monomer mechanism) [117] and, more recently, for $N$-carboxyanhydrides of $\alpha$-amino acids [118-120].

During the 1970s, when the field of living cationic ROP underwent extensive development, the absolute rate constants were determined only for THF [106]. Nonetheless, a number of kinetic investigations were conducted with the cationic polymerization of substituted aziridines [121] and 1,3-oxazolines [122-124], and this in turn led to the revelation of a variety of attributes of 'livingness' associated with these processes.

It should also be noted that the anionic and cationic polymerization of cyclic trisiloxanes were both found to be devoid of termination and irreversible transfer, such that-in principle - the criteria of the living process were fulfilled. In contrast, 
the rapid and reversible reactions which occur in the system compete effectively with propagation, such that the molar masses of the resultant siloxanes, their distribution, and the structure of the end groups cannot be precisely controlled (see Sections 2.2.2.1 and 3.3 in Ref. [12]).

\subsubsection{Kinetic Criteria of Living Polymerization}

The kinetic scheme of living, reversible ROP can also encompass-apart from initiation (Equation 1.27a) and propagation (Equation 1.27b)-additional reversible reactions, such as segmental exchange (Equation $1.27 \mathrm{c}$ ) or temporary termination (Equation 1.27d).

$$
\begin{aligned}
& \mathrm{I}+\mathrm{M} \stackrel{\mathrm{k}_{\mathrm{i}}}{\longrightarrow} \mathrm{P}_{1}^{*} \\
& \mathrm{P}_{\mathrm{n}}^{*}+\mathrm{M} \underset{k_{\mathrm{d}}}{\stackrel{k_{\mathrm{p}}}{\rightleftharpoons}} \mathrm{P}_{\mathrm{n}+1}^{*} \\
& \mathrm{P}_{\mathrm{x}}^{*}+\mathrm{P}_{\mathrm{y}}^{*} \underset{k_{\mathrm{tr} 2}}{\stackrel{k_{\mathrm{tr} 2}}{\rightleftharpoons}} \mathrm{P}_{\mathrm{x}-\mathrm{z}}^{*}+\mathrm{P}_{\mathrm{y}+\mathrm{z}}^{*} \\
& \mathrm{P}_{\mathrm{n}}^{*}+\mathrm{T} \underset{k_{\mathrm{a}}}{\stackrel{k_{\mathrm{da}}}{\rightleftharpoons}} \mathrm{P}_{\mathrm{n}}
\end{aligned}
$$

where $\mathrm{P}_{\mathrm{i}}^{*}$ denotes the living macromolecule, $\mathrm{T}$ is the deactivating agent, $\mathrm{P}_{\mathrm{n}}$ is the temporary deactivated macromolecule, $k_{\mathrm{tr} 2}$ is the rate constant of the bimolecular transfer to polymer with chain rupture, and $k_{\mathrm{da}}$ and $k_{\mathrm{a}}$ are the rate constants of temporary deactivation and activation, respectively.

In spite of the side reactions (Equations 1.27c and d) that may take place, the polymerization described by Equation 1.27 meets the criteria of the living process, provided that the activation is sufficiently fast (i.e. $k_{\mathrm{a}} \geq k_{\mathrm{p}}[\mathrm{M}]$ ) since, under this condition, the system comprises exclusively macromolecules that are capable of growth.

In the case of rapid initiation and reversible propagation being the only reactions in the polymerizing system, and proceeding only with one kind of active center, the expression for the polymerization rate (assuming the independence of $k_{\mathrm{p}}$ on $D P_{\mathrm{n}}$ ) reads:

$$
R_{\mathrm{p}}=-\frac{d[\mathrm{M}]}{d \mathrm{t}}=k_{\mathrm{p}} \Sigma\left[\mathrm{P}_{\mathrm{n}}^{*}\right][\mathrm{M}]-k_{\mathrm{d}} \Sigma\left[\mathrm{P}_{\mathrm{n}}^{*}\right]
$$

Integration of Equation 1.28 leads to the well-recognized semilogarithmic dependence of monomer concentration on polymerization time:

$$
\ln \frac{[\mathrm{M}]_{0}-[\mathrm{M}]_{\mathrm{eq}}}{[\mathrm{M}]-[\mathrm{M}]_{\mathrm{eq}}}=k_{\mathrm{p}} \Sigma\left[\mathrm{P}_{\mathrm{n}}^{*}\right] t=k_{\mathrm{p}}[\mathrm{I}]_{0} \mathrm{t}
$$

For the strained three- and four-membered monomers, $[\mathrm{M}]_{\mathrm{eq}} \approx 0$. However, the need to insert $[\mathrm{M}]_{\mathrm{eq}}$ into Equation 1.29 for the higher-membered monomers seems self-evident. Moreover, the $[\mathrm{M}]_{\mathrm{eq}}$ value determined under the exact polymerization conditions must be used since, in the past serious errors have been made in the 
kinetic analysis of THF polymerization due to incorrect values of [THF $]_{\mathrm{eq}}$ being applied (for a more detailed discussion, see Ref. [56]). Likewise, in the example of LA polymerization conducted at an elevated temperature (e.g. $80^{\circ} \mathrm{C}$, at which $\left.[\mathrm{LA}]_{\mathrm{eq}}=0.055 \mathrm{moll}^{-1}\right)$, the simplified equation $\ln \left([\mathrm{M}]_{0} /[\mathrm{M}]\right)=k_{\mathrm{p}}[\mathrm{I}]_{0} \mathrm{t}$, is occasionally used. This results in incorrect kinetic plots, especially for any relatively low concentrations of the starting monomer (e.g. $[\mathrm{LA}]_{0} \leq 1 \mathrm{moll}^{-1}$ ).

The $D P_{\mathrm{n}}$ of the growing living polymer is a simple, linear function of monomer conversion (assuming that $k_{\mathrm{i}} \geq k_{\mathrm{p}}$ ):

$$
D P_{\mathrm{n}}=\frac{[\mathrm{M}]_{0}-[\mathrm{M}]}{[\mathrm{I}]_{0}}=\frac{\left.[\mathrm{M}]_{0}\right]}{[\mathrm{I}]_{0}} \times \frac{[\mathrm{M}]_{0}-[\mathrm{M}]}{[\mathrm{M}]_{0}} ; \quad[\mathrm{I}]_{0}=\Sigma\left[\mathrm{P}_{n}^{*}\right]
$$

Thus, plots of $\ln \left\{\left([\mathrm{M}]_{0}-[\mathrm{M}]_{\mathrm{eq}}\right) /\left([\mathrm{M}]-[\mathrm{M}]_{\mathrm{eq}}\right)\right\}$ on time and $D P_{\mathrm{n}}\left(M_{n}\right)$ on monomer conversion $\left(\left([\mathrm{M}]_{0}-[\mathrm{M}]\right) /[\mathrm{M}]_{0}\right)$ are typically used as a criterion of polymerization livingness. An example of experimental points placed on these coordinates is shown in Figure 1.8 [98].

Two sets of points are used on the kinetic plot (Figure 1.8a); one set is for conversion as measured by SEC, and the other set for conversion determined from polarimetric readings. The linearity of this plot from the very start of the polymerization points to a rapid initiation and an absence of chain termination. The molar mass evolution plot (Figure 1.8b) is also linear, and fits the theoretical line which is calculated by assuming the starting $[\mathrm{M}]_{0}$ and $[\mathrm{I}]_{0}$ concentrations (Equation 1.30). This result reveals the initiation to be both rapid and quantitative-that is,

(a)

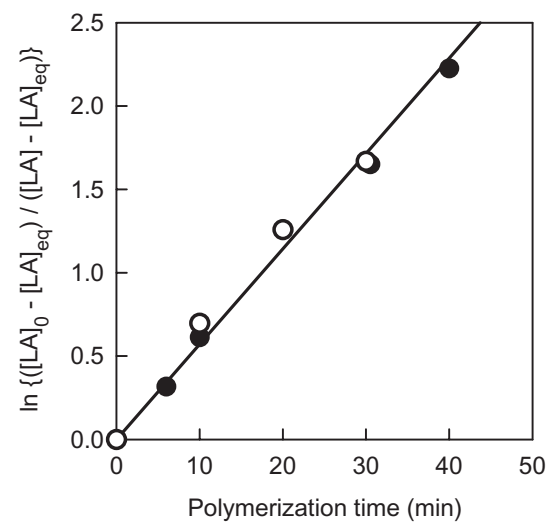

(b)

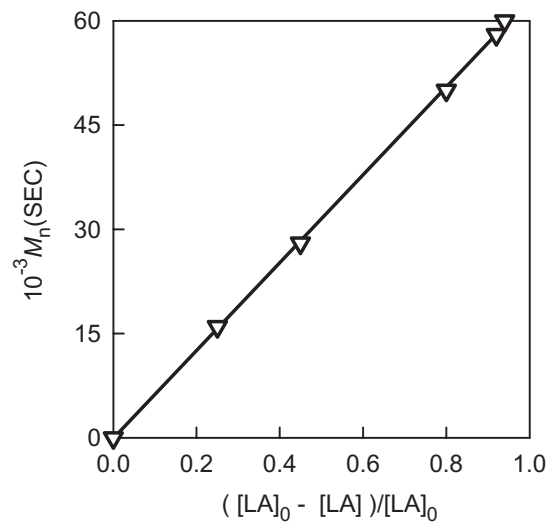

Figure 1.8 (a) Semilogarithmic kinetic plot and (b) molar masses evolution with monomer conversion, determined in the polymerization of L,L-lactide (LA) initiated with $\mathrm{Sn}(\mathrm{OBu})_{2}$. Conditions: $[\mathrm{LA}]_{0}=1.0 \mathrm{moll}^{-1},\left[\mathrm{Sn}(\mathrm{OBu})_{2}\right]_{0}=1.16 \times 10^{-3} \mathrm{moll}^{-1}$, THF solvent, $80^{\circ} \mathrm{C}$. Concentration of [LA] monitored by SEC $(\bullet)$ and polarimetry $(O)$ [98]. 
each molecule of the difunctional initiator $\left(\mathrm{Sn}(\mathrm{OBu})_{2}\right)$ begins the growth of exactly two macromolecules from one $\mathrm{Sn}(\mathrm{II})$ atom (Equation 1.31).

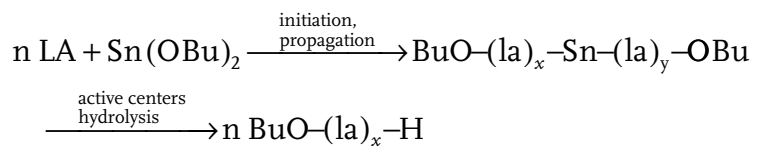

The slow initiation results typically in a positive curvature (acceleration) of the kinetic plot, but in a negative curvature for the molar mass evolution plot (see e.g. the slow initiation case in the $\mathrm{LA} / \mathrm{Al}\left(\mathrm{O}^{i} \mathrm{Pr}\right)_{3}$ tetramer system [125a]). Beste and Hall [125b], and later also Pepper [125c], each described methods of trial and error analysis which allowed the determination $k_{\mathrm{i}}$ and $k_{\mathrm{p}}$ values on the basis of experimental $[\mathrm{M}]$ versus time data (an example is provided in Ref. [125d]). More recently, however, less-cumbersome computational methods starting from kinetic Equations 1.27a and $b$ have more often been employed (see e.g. Ref. [125a]).

Interestingly, a slow initiation does not lead to an especially broad molar mass distribution, and in this case (assuming that other reactions leading to higher polymer dispersities can be excluded), the Gold distribution is applicable. Therefore, whilst $D \leq 1.4$ can be expected even for $k_{\mathrm{p}} / k_{\mathrm{i}}$ ratios higher than $10^{3}$ [126], the molar mass of the resultant polymer can barely be controlled.

It should also be noted that termination inevitably leads to a decrease in the polymerization rate, which in turn causes a negative curvature of the kinetic plot, although this side reaction does not cause any change in the linear molar mass evolution plot.

Some time ago, the two above-discussed criteria of livingness were taken together to yield a dependence [127]:

$$
-\ln \left(1-\frac{[\mathrm{I}]_{0}}{[\mathrm{M}]_{0}-[\mathrm{M}]_{\mathrm{eq}}} D P_{\mathrm{n}}\right)=k_{\mathrm{p}}[\mathrm{I}]_{0} \mathrm{t}
$$

The linearity of the $-\ln \left\{1-D P_{\mathrm{n}}[\mathrm{I}]_{0} /\left([\mathrm{M}]_{0}-[\mathrm{M}]_{\mathrm{eq}}\right)\right\}$ versus time plot, in the instance of fast initiation, provides a both necessary and sufficient criterion of livingness. The third plot, which combines the two plots from Figure 1.8, is shown in Figure 1.9. Again, the linearity of the plot corresponds to the living and controlled character of LA polymerization initiated with $\mathrm{Sn}(\mathrm{OBu})_{2}$.

\subsubsection{Active Center Interconversions and the Determination of Absolute Rate Constants}

Active centers are formed on the first addition of monomer to initiator. Since, for purposes of controlled polymerization, this step must be both rapid and quantitative, there is no need to discuss the initiation step separately at this point.

Recent methods used to determine the chemical structures and/or concentrations of active centers in ROP elaborated $[23,24]$ were mostly based on direct 


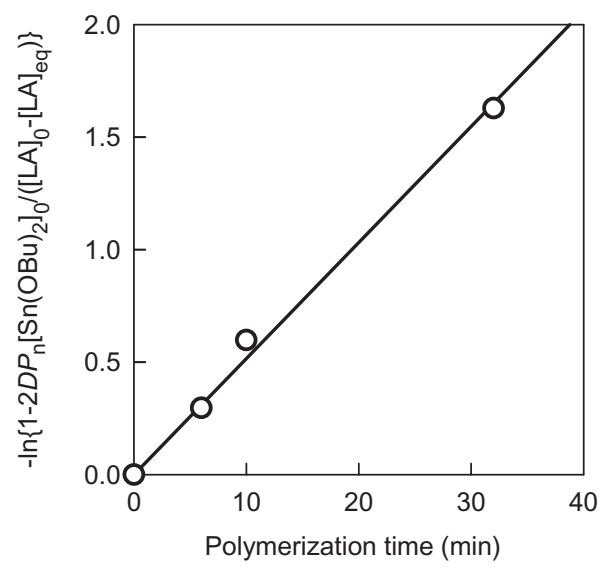

Figure 1.9 Dependence of $-\ln \left\{1-2 D P_{n}\left[\mathrm{Sn}(\mathrm{OBu})_{2}\right]_{0} /\right.$ $\left.\left([L A]_{0}-[L A]_{e q}\right)\right\}$ on time. The conditions of polymerization were as in Figure 1.8.

spectroscopic measurements of the living polymerization mixtures (e.g. ${ }^{1} \mathrm{H}$ NMR [128-136], ${ }^{27} \mathrm{Al}$ NMR [137]) or of end-capped structures, for example with Pcontaining agents (phosphines in cationic $[138,139]$ or diphenylchlorophosphorane in anionic polymerization [140]) by using ${ }^{31} \mathrm{P}$ NMR.

The determination of chemical structure is necessary-but not always adequatefor providing a complete description of the polymerization process. In particular, for ionic polymerization a variety of physical forms of active center exists, including (free) ions, ion pairs (contact or separated), ion pair aggregates, covalent species and their aggregates, all of which are in equilibrium [141]. Each of these structures can participate in propagation processes, with their own rate constant (Scheme 1.3). To the best of our knowledge, covalent-ionic species interconversions have been observed only in cationic polymerization [23, 24], whereas ion pair and covalent species aggregation is characteristic of anionic and coordination (pseudoanionic) processes, respectively [8b]. However, in cationic process ion pairs may also undergo aggregation at higher concentrations.

1.3.2.2.1 Reactivities of Ions and Ion Pairs Aggregation in anionic polymerization can be eliminated by the complexation of counterions with crown ethers [112] or cryptands [113]) and/or by the application of polar solvents such as hexamethylphosphotriamide (HMPT), dimethyl sulfoxide (DMSO) or dimethyl formamide (DMF) [142]. The $K_{\mathrm{D}}$ in systems devoid of ion pair aggregation can be determined from conductometric measurements [141a]. The fraction of ions $(\alpha)$ in the polymerizing mixture depends directly on $K_{\mathrm{D}}$ and the total concentration of ionic species (ions and ion pairs). In the living polymerization with a fast initiation, the latter is equal to the starting concentration of the initiator $\left([\mathrm{I}]_{0}\right)$. The corresponding Equation 1.33 can be derived directly, starting from the expression for an ion pair-ion equilibrium constant. 
(a) Anionic polymerization

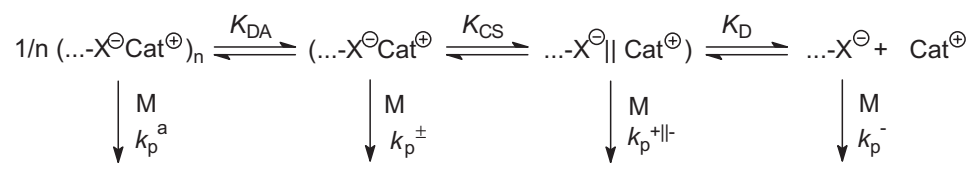

(b) Cationic polymerization

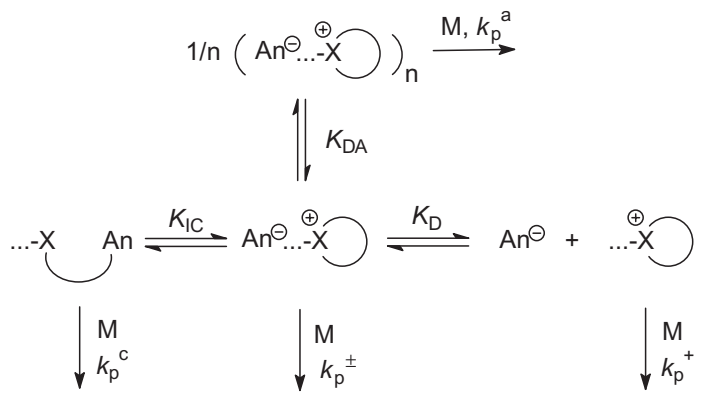

(c) Coordination (pseudoanionic) polymerization

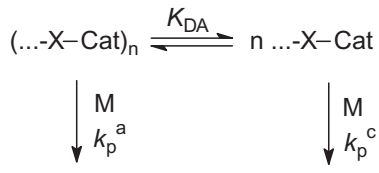

$\mathrm{Cat}^{\oplus}, \quad \mathrm{An}^{\ominus}=$ counterions

$\mathrm{X}=$ heteroatom or group containing heteroatoms; $\mathrm{M}=$ monomer molecule.

$K_{\mathrm{DA}}, K_{\mathrm{CS}}, K_{\mathrm{D}}, K_{\mathrm{IC}}=$ equilibrium constants of disaggregation, between contact and

separated ion pairs, of dissociation, and of ion pair to covalent species collapse, respectively.

$k_{\mathrm{p}}^{\mathrm{c}}, k_{\mathrm{p}}{ }^{\mathrm{a}}, k_{\mathrm{p}}^{ \pm}, k_{\mathrm{p}}{ }^{+\|-}$and $k_{\mathrm{p}}^{-}=$corresponding rate constants of propagation.

Scheme 1.3 Equilibria between various structures of active species in ROP.

$$
\begin{aligned}
& \alpha=\frac{K_{\mathrm{D}}}{2[\mathrm{I}]_{0}}\left(\sqrt{1+4 \frac{[\mathrm{I}]_{0}}{K_{\mathrm{D}}}}-1\right) \\
& \alpha=\sqrt{\frac{K_{\mathrm{D}}}{[\mathrm{I}]_{0}}}
\end{aligned}
$$

Equation $1.33 \mathrm{~b}$ is obtained from Equation 1.33a by introducing the assumption that $[\mathrm{I}]_{0} / K_{\mathrm{D}} \gg 1$, which is valid for weak electrolytes.

Values of $K_{\mathrm{D}}$ for alkoxide, thiolate and carboxylate species with $\mathrm{Li}^{+}, \mathrm{Na}^{+}$or $\mathrm{K}^{+}$ counterions, determined in the anionic polymerization of EO and CL, ethylene sulfide (thiirane) and PL polymerization, lie in a very broad range of values, from 
$\approx 10^{-10}$ up to $\approx 10^{-4} \mathrm{moll}^{-1}$ (cf. Table 3.4 in Ref. [24] and Table 4.1 in Ref. [12]). Low $K_{\mathrm{D}}$ values, which are characteristic of polymerizations conducted in THF without cation-complexing agents, increase considerably after the addition of cryptand or crown ether and/or polymerization in polar solvents. Thus, in the former case active centers are present exclusively in the ion pair form, whilst in the latter case the fraction of free ions may be considerably higher, especially for the low total concentration of active centers.

In contrast, in the cationic polymerization of cyclic ethers (e.g. THF or sevenmembered oxepane), the dissociation equilibrium constants have considerably higher values, depending on the solvent polarity: $K_{\mathrm{D}} \approx 10^{-5} \mathrm{moll}^{-1}\left(\mathrm{CH}_{2} \mathrm{Cl}_{2}\right)$ and $\approx 10^{-3} \mathrm{moll}^{-1}\left(\mathrm{CH}_{3} \mathrm{NO}_{2}, \mathrm{C}_{6} \mathrm{H}_{5} \mathrm{NO}_{2}\right)$ with $\mathrm{SbCl}_{6}{ }^{-}$as a counterion (see Table 8 in Ref. [3a]).

This pronounced difference between anionic and cationic polymerizations can be attributed to the fact that, in anionic centers, the negative charge is concentrated on the heteroatom(s), whereas in cationic centers (e.g. oxonium ions) the positive charge is located not on the oxygen atom but rather on the adjacent carbon and hydrogen atoms [143].

Thus, in ionic polymerization the results of kinetic measurements performed for a single set of conditions $\left([\mathrm{M}]_{0},[\mathrm{I}]_{0}\right.$, solvent and temperature) and then inserted into the $\ln \left\{\left([\mathrm{M}]_{0}-[\mathrm{M}]_{\mathrm{eq}}\right) /\left([\mathrm{M}]_{0}-[\mathrm{M}]\right)\right\}$-time coordinates (Equation 1.29), provide only an apparent rate constant $\left(k_{\mathrm{p}}\right)$, when several types of active centers are in operation. For example, in the anionic polymerization case:

$$
k_{\mathrm{p}}=k_{\mathrm{p}}^{ \pm}+\left(k_{\mathrm{p}}^{-}-k_{\mathrm{p}}^{ \pm}\right) \alpha
$$

Thus, by combining Equations 1.29, 1.33b and 1.34 one obtains:

$$
k_{\mathrm{p}}=k_{\mathrm{p}}^{ \pm}+\left(k_{\mathrm{p}}^{-}-k_{\mathrm{p}}^{ \pm}\right) \sqrt{\frac{K_{\mathrm{D}}}{[\mathrm{I}]_{0}}}
$$

In order to determine the absolute rate constants $k_{\mathrm{p}}^{ \pm}$and $k_{\mathrm{p}}^{-}$it is necessary to measure $k_{\mathrm{p}}$ for various degrees of dissociation $\alpha$ (i.e. by changing $[\mathrm{I}]_{0}$; see Equation 1.35). $k_{\mathrm{p}}^{ \pm}$and $k_{\mathrm{p}}^{-}$can then be evaluated from $k_{\mathrm{p}}$ on the $\left(K_{\mathrm{D}} /[\mathrm{I}]_{0}\right)^{1 / 2}$ plot, where the intercept gives $k_{\mathrm{p}}^{ \pm}$and the slope gives $k_{\mathrm{p}}^{-}-k_{\mathrm{p}}^{ \pm}$.

In anionic ROP, $k_{\mathrm{p}}^{ \pm}$and $k_{\mathrm{p}}^{-}$were determined for a number of monomer/ counterion/solvent systems [24]. Results obtained for CL polymerization was typical for a majority of other systems; namely, alkoxide macroions were much more reactive than alkoxide macroion pairs: for example $k_{\mathrm{p}}^{-}=3.5 \times 10^{2} \mathrm{~mol}^{-1} 1 \mathrm{~s}^{-1}$, whereas $k_{\mathrm{p}}^{ \pm}=4.8$ and $5 \mathrm{~mol}^{-1} 1 \mathrm{~s}^{-1}$ for the $\mathrm{K}^{+}$[144] and $\mathrm{K}^{+} / 18$-dibenzo-crown- 6 ether (DBC) [102] counterions, respectively (THF solvent, $20^{\circ} \mathrm{C}$ ). Interestingly, the enthalpy of activation for the macroions $\left[\Delta H_{\mathrm{p}}^{\neq}(-)=39.2 \mathrm{kJmol}^{-1}\right]$ was higher than that for macroion pairs $\left[\Delta H_{\mathrm{p}}^{\neq}( \pm)=13.7 \mathrm{~kJ} \mathrm{~mol}^{-1}\right]$. Therefore, below a certain temperature-the temperature of inversion $\left(T_{\mathrm{i}}\right)$-the reactivity of macroions should be lower than that of the macroion pairs (Equation 1.26). The $T_{\mathrm{i}}$ calculated from the thermodynamic parameters of activation for macroions and macroion pairs 
(Equation 1.26) was equal to $-64^{\circ} \mathrm{C}$ [102]. For PL propagating on carboxylate species with a $\mathrm{K}^{+} / \mathrm{DBC}$ counterion in DMF as solvent, $T_{\mathrm{i}}$ was found experimentally to be equal to $20^{\circ} \mathrm{C}$ [142].

The plausible explanation for this striking phenomenon states that:

“... that around the macroion pair $(\Theta, \oplus)$ solvent $(\mathrm{S})$ and monomer (M) molecules ... are packed disorderly in the available space and being not oriented in any specific way. On the contrary, macroion is specifically solvated, and the thermodynamic potential of the monomer molecules solvating the active species differ from this of monomer in solution. The lower the temperature the more perfect becomes the solvation shell around ions and removal of solvent and/or monomer molecules, a necessary step preceding propagation, becomes more and more difficult. Thus, the activity of ions decreases faster with lowering temperature than the reactivity of ion pairs, where the solvation is not important. Then, at certain temperature, reactivities become equal one to another, which is followed by their inversion after further temperature decrease" [12].

A similar inversion of reactivities was also reported for thiolate active centers with alkali metal counterions complexed with cryptates, in propylene sulfide (2-methylthiirane) polymerization [111].

The absolute rate constants of propagation have also been determined in cationic ROP [145-148], although full kinetic analyses have only been performed for THF [146], oxepane [147] and conidine [148] polymerization.

In contrast to anionic ROP (and to anionic vinyl polymerization), the reactivities of macroions and macroion pairs were found to equate, within experimental error. For example, in the polymerization of THF, $k_{\mathrm{p}}^{+}=k_{\mathrm{p}}^{ \pm}=6.0 \times 10^{-4} \mathrm{~mol}^{-1} 1 \mathrm{~s}^{-1}\left(\mathrm{SbCl}_{6}^{-}\right.$ counterion, $\left.\mathrm{CH}_{2} \mathrm{Cl}_{2}, 25^{\circ} \mathrm{C}\right)$ or $4.7 \times 10^{-4} \mathrm{~mol}^{-1} 1 \mathrm{~s}^{-1}\left(\mathrm{SbCl}_{6}^{-}, \mathrm{C}_{6} \mathrm{H}_{5} \mathrm{NO}_{2}, 25^{\circ} \mathrm{C}\right)$.

The observation that for THF, $k_{\mathrm{p}}^{+}=k_{\mathrm{p}}^{ \pm}$, seems to be a general feature of cationic $\mathrm{ROP}$, and at least two reasons have been proposed for this important feature to occur. As explained in Ref. [12]:

“... The first is related to the size of active species; due to the large size of anions the Coulombic attractions between cation and anion are relatively weak and the nature of anion does not affect significantly the reactivity of cation. The second explanation is based on the assumed mechanism of the propagation step. Counterion is a 'large ball under the relatively steep roof' and it can be further visualized that this ball (counterion) flows to the new position when the monomer adds to the oxonium ion, in which over $90 \%$ of the positive charge is 
located on the $\mathrm{CH}_{2}$ groups. This is an additional argument that the counterion does not have to be removed far away from its position in the ground state to the transition state during the propagation step, and there is no reason for the activation energies for the propagation step on ions or ion-pairs to differ substantially. Thus, $k_{\mathrm{p}}^{+} \approx k_{\mathrm{p}}^{ \pm}$, as found experimentally, is not surprising for these systems. In the anionic ring-opening propagation discussed earlier; the negative charge is localized (e.g. in the alkoxide anion) while the size of counteraction is usually rather small. Thus, the monomer addition requires an extensive charge separation in the ion pairs."

Another general feature of the cationic process is that $k_{\mathrm{p}}^{\mathrm{i}}\left(=k_{\mathrm{p}}^{+}=k_{\mathrm{p}}^{ \pm}\right)$with a given onium cation increase with increasing nucleophilicity of the monomer, whereas for a given monomer $k_{\mathrm{p}}^{\mathrm{i}}$ there is a decrease with increasing nucleophilicity of the heteroatom in the onium active species. However, the observed net result is that $k_{\mathrm{p}}^{\mathrm{i}}$ depends on the cyclic monomer nucleophilicity-that is, it increases in the order: amines $<$ oxazolines $<$ sulfides $<$ ethers $<$ acetals [107].

\subsection{Kinetics of Propagation in Systems with Growing-Dormant Centers}

Equilibria Growing-active species equilibria (Equation 1.27d), which was first observed by Szwarc during the early 1960s in the anionic polymerization of styrene [149], play a fundamental role in polymer chemistry, as an understanding of these phenomena led to the creation of a solid base for the development of controlled cationic [150] and radical [151] vinyl polymerizations. These types of equilibria were also observed in the living ROP.

Cationic Polymerization Growing-dormant species equilibria in cationic ROP have another origin than that in anionic or coordination processes. Namely, certain ion pair counterions, such as $\mathrm{CH}_{3} \mathrm{SO}_{3}{ }^{-}, \mathrm{CF}_{3} \mathrm{SO}_{3}{ }^{-}$or $\mathrm{ClO}_{4}^{-}$, react with onium cations in the active center, using two electrons of the oxygen atom to create a covalent bond. Therefore, whenever polymerization proceeds with these anions, reversible ester formation may take place (e.g. in THF polymerization with $\mathrm{CF}_{3} \mathrm{SO}_{3}{ }^{-}$counterion the $-\mathrm{OCH}_{2} \mathrm{CH}_{2} \mathrm{CH}_{2} \mathrm{CH}_{2} \mathrm{OSO}_{2} \mathrm{CF}_{3}$ ester is formed) [3a, 23, 106]. The relative concentrations of macroesters and macroion-pairs in solvents of very different polarity, namely $\mathrm{CCl}_{4}, \mathrm{CH}_{2} \mathrm{Cl}_{2}$ and $\mathrm{CH}_{3} \mathrm{NO}_{2}$, vary dramatically. There are almost no ions in $\mathrm{CCl}_{4}$, and almost no covalent species in $\mathrm{CH}_{3} \mathrm{NO}_{2}$. The covalent bond formation has important consequences due to the very low reactivity of the resultant macroester species.

When the ionic (ions and ion pairs of equal reactivity, without regard for the counterion structure) and covalent species operate simultaneously, such that the apparent rate constant $\left(k_{\mathrm{p}}\right)$ is a resultant of the absolute rate constants $k_{\mathrm{p}}^{\mathrm{i}}$ and $k_{\mathrm{p}}^{\mathrm{c}}$ and proportions of ionic $(\beta)$ and covalent species $(1-\beta)$ : 


$$
k_{\mathrm{p}}=\beta k_{\mathrm{p}}^{i}+(1-\beta) k_{\mathrm{p}}^{c}
$$

The $k_{\mathrm{p}}$ is determined experimentally from the $\ln \left\{\left([\mathrm{M}]_{0}-[\mathrm{M}]_{\mathrm{eq}}\right) /\left([\mathrm{M}]-[\mathrm{M}]_{\mathrm{eq}}\right)\right\}$ on time plot (Equation 1.29). If the proportions of ionic and covalent species are known (for example, from ${ }^{1} \mathrm{H}$ NMR measurements [128]), then $k_{\mathrm{p}}^{\mathrm{c}}$ may be determined from one kinetic run. In the polymerization of THF performed in solvents of different polarity, the following $k_{\mathrm{p}}^{\mathrm{c}}$ values were determined: $6 \times 10^{-5} \mathrm{~mol}^{-1} 1 \mathrm{~s}^{-1}$ $\left(\mathrm{CCl}_{4}\right)$ and $5 \times 10^{-4} \mathrm{~mol}^{-1} 1 \mathrm{~s}^{-1}\left(\mathrm{CH}_{3} \mathrm{NO}_{2}\right)\left([\mathrm{THF}]_{0}=8 \mathrm{moll}^{-1}, 25^{\circ} \mathrm{C}\right)[56]$. In concluding, the reactivity of covalent species is approximately three orders of magnitude lower than that of ionic species, and therefore the ionic species, even if present in a small fraction, are almost exclusively responsible for the propagation. The results of recent studies with of 2-methyl oxazoline cationic polymerization have led to similar conclusions [124].

A complete description of the cationic polymerization of THF, including all rate constants for the ionic and covalent species interconversions, and methods of their determination, may be found in Chapter 5 of Ref. [3a]. For a more concise description, however, see Section 3.1.1 in Ref. [12].

Anionic and Coordination Polymerization Aggregates of ion pairs, or of covalent species formed reversibly in the anionic or pseudoanionic polymerization of EO [152, 153], cyclosiloxanes [154] and cyclic esters [79, 155-157], were found to be essentially unreactive; thus, in polymer chain growth only unimeric, deaggregated species will participate. The pertinent kinetic scheme reads:

$$
\begin{aligned}
& \mathrm{P}_{\mathrm{i}}^{*}+\mathrm{M} \stackrel{\mathrm{k}_{\mathrm{p}}}{\longrightarrow} \mathrm{P}_{\mathrm{i}+1}^{*} \\
& \mathrm{mP}_{\mathrm{i}}^{*} \stackrel{\mathrm{K}_{\mathrm{A}}}{\rightleftharpoons}\left(\mathrm{P}_{\mathrm{i}}^{*}\right)_{\mathrm{m}} \\
& \left(\mathrm{P}_{\mathrm{i}}^{*}\right)_{\mathrm{m}}+\mathrm{M} \stackrel{\text { no reaction }}{\longrightarrow}
\end{aligned}
$$

A solution of the kinetics shown in Equation 1.37 provides two useful dependences $[155,156]$ :

$$
\begin{aligned}
& \ln r_{\mathrm{p}}=\ln k_{\mathrm{p}}\left(m K_{\mathrm{A}}\right)^{-1 / m}+\frac{1}{m} \ln [\mathrm{I}]_{0} \\
& r_{\mathrm{p}}^{1-m}=-m K_{\mathrm{A}} k_{\mathrm{p}}^{1-m}+k_{\mathrm{p}}[\mathrm{I}]_{0} r_{\mathrm{p}}^{-m}
\end{aligned}
$$

where $r_{\mathrm{p}}=d[\mathrm{M}] /[\mathrm{M}] d \mathrm{t}=t^{-1} \ln \left([\mathrm{M}]_{0} /[\mathrm{M}]\right)$, and $[\mathrm{I}]_{0}$ is the starting concentration of initiator [this is equal, at the correctly chosen (living) conditions, to the total concentration of active centers, both growing and dormant (for CL at room temperature $\left.\left.[\mathrm{M}]_{\mathrm{eq}} \approx 0\right)\right]$.

Fitting the experimental data (i.e. $r_{\mathrm{p}}$ and $[\mathrm{I}]_{0}$ ) available from the kinetic measurements to Equation 1.38a allows determination of the degree of aggregation $(m)$. 


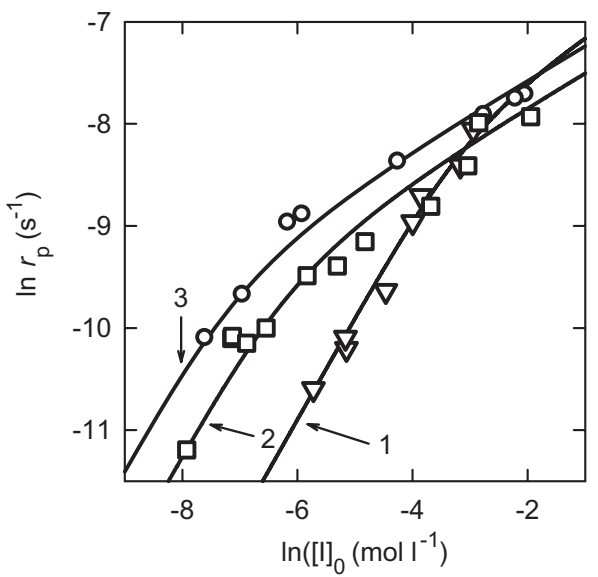

Figure 1.10 External order of initiator dependencies (Equation 1.37a) obtained in polymerization of $\varepsilon$-caprolactone $(C L)$ initiated with $\mathrm{Et}_{2} \mathrm{AlOEt}$. Conditions: $[\mathrm{CL}]_{0}=2 \mathrm{moll}^{-1}$, solvents: $\mathrm{CH}_{3} \mathrm{CN}$ (curve 1), THF (curve 2), $\mathrm{C}_{6} \mathrm{H}_{6}$ (curve 3); temperature $25^{\circ} \mathrm{C}$. The points represent experimental data; the lines were computed numerically, assuming kinetic Equation 1.37a-c [157].

Figure 1.10 shows an example of the $r_{\mathrm{p}}$ versus $[\mathrm{I}]_{0}$ dependencies (Equation 1.38a) obtained in the polymerization of CL initiated with $\mathrm{Et}_{2} \mathrm{AlOEt}$ and carried out in $\mathrm{CH}_{3} \mathrm{CN}$, THF and $\mathrm{C}_{6} \mathrm{H}_{6}$ as solvents [157]. The resultant plots reveal that the order in initiator in all solvents decreases from 1 to $1 / 3$ with increasing total concentrations of active centers (equivalent to $[\mathrm{I}]_{0}$ in the living polymerization conditions). This behavior points clearly to the aggregation of unimeric aluminum alkoxide $\left.(-\mathrm{C}=\mathrm{O}) \mathrm{CH}_{2} \mathrm{CH}_{2} \mathrm{CH}_{2} \mathrm{CH}_{2} \mathrm{CH}_{2} \mathrm{O}-\mathrm{AlEt}_{2}\right)$ active centers into the unreactive trimers.

Unfortunately, this approach does not allow the separate determination of $K_{\mathrm{a}}$ and $k_{\mathrm{p}}$, but only their product. A method to determine both $k_{\mathrm{p}}$ and $K_{\mathrm{a}}$ is possible, however, particularly when the degree of aggregation can be estimated in the manner described above. For this, Equation $1.38 \mathrm{~b}$ provides a direct access to both $k_{p}$ and $K_{\mathrm{a}}$. The power of this analytical approach can be seen by comparing the two figures taken from Ref. [105] (Figure 1.11).

Although the degree of aggregation has long been known to equal 3 for polymerizations conducted with diethyl aluminum alkoxide, a decision was taken also to check results when deliberately introducing an incorrect aggregation number of 2 . The resultant plot produced highly dispersed points, unlike the typical straight line obtained with a value of 3 .

Values of $k_{\mathrm{p}}$ and $K_{\mathrm{a}}$ determined for the CL/Et ${ }_{2} \mathrm{AlOEt}$ system in solvents of various polarities and solvating power are collected in Table 1.2. These data reveal that, the higher dielectric constant of the solvent, the lower are both $k_{\mathrm{p}}$ and $K_{\mathrm{A}}$. Namely, an increase in $\varepsilon$ from 2.3 to 37 causes a decrease in $k_{\mathrm{p}}$ from $8.6 \times 10^{-2}$ to $7.5 \times 10^{-3} \mathrm{~mol}^{-1} 1 \mathrm{~s}^{-1}$ (i.e. 11-fold) and a simultaneous decrease in $K_{\mathrm{A}}$, from $2.4 \times 10^{5}$ 

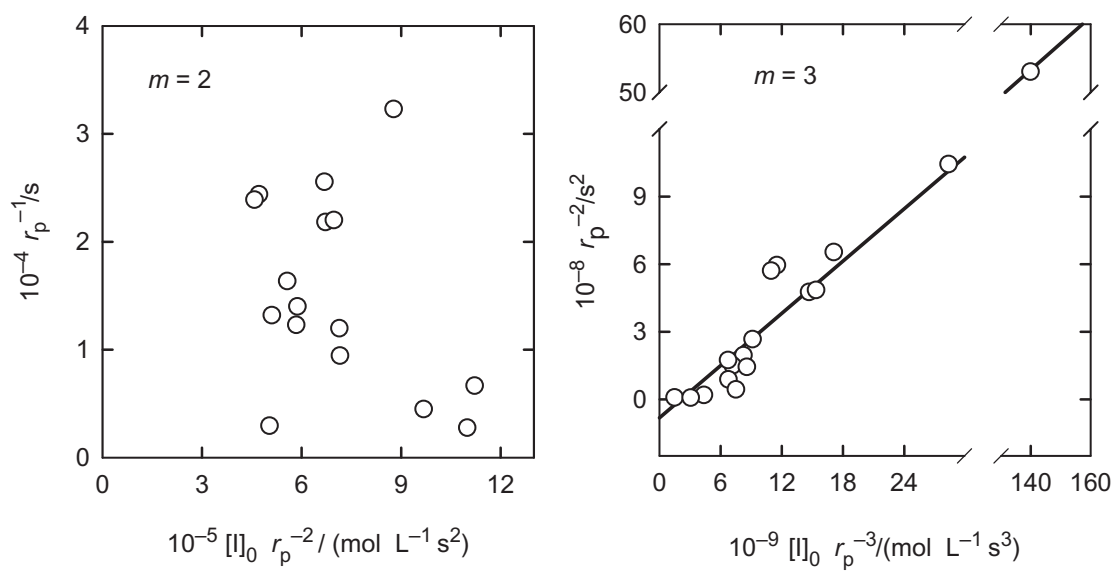

Figure 1.11 Polymerization of $\varepsilon$-caprolactone (CL) initiated with $\mathrm{Et}_{2} \mathrm{AlOEt}\left(\mathrm{THF}, 25^{\circ} \mathrm{C}\right)$. Test of Equation 1.37b for degree of aggregation, $m$. Only for $m=3$ was a straight line obtained as required. (The primary kinetic data were taken from Ref. [156].)

Table 1.2 Absolute propagation rate constants $\left(k_{\mathrm{p}}\right)$ and equilibrium constants of aggregation $\left(K_{A}\right)$ for polymerization of $\varepsilon$-caprolactone initiated by diethylaluminum ethoxide ${ }^{a}$ [157]

\begin{tabular}{llll}
\hline Solvent & Dielectric constant $(\varepsilon)$ & $\frac{\boldsymbol{k}_{\mathbf{p}}}{\mathbf{m o l}^{-\mathbf{1}} \mathbf{L} \mathbf{s}^{-\mathbf{1}}}$ & $\frac{\boldsymbol{K}_{\mathbf{A}}}{\mathbf{m o l}^{-\mathbf{2} \mathbf{L}^{\mathbf{2}}}}$ \\
\hline $\mathrm{CH}_{3} \mathrm{CN}$ & 37 & $7.5 \times 10^{-3}$ & $7.7 \times 10^{1}$ \\
$\mathrm{THF}$ & 7.3 & $3.9 \times 10^{-2}$ & $5.5 \times 10^{4}$ \\
$\mathrm{C}_{6} \mathrm{H}_{6}$ & 2.3 & & $2.4 \times 10^{5}$ \\
\hline
\end{tabular}

a $\quad[\mathrm{CL}]_{0}=2 \mathrm{moll}^{-1}, 25^{\circ} \mathrm{C}$.

to $7.7 \times 10 \mathrm{~mol}^{-2} \mathrm{l}^{2}$. Therefore, for the lower total concentrations of active centers when the nonaggregated, actually growing species dominate (Figure 1.10), the polymerization rates order, measured for a given $[\mathrm{I}]_{0}$ is as follows: $r_{\mathrm{p}}\left(\mathrm{C}_{6} \mathrm{H}_{6}\right)>r_{\mathrm{p}}$ $(\mathrm{THF})>r_{\mathrm{p}}\left(\mathrm{CH}_{3} \mathrm{CN}\right)$. However, for a higher $[\mathrm{I}]_{0}$, when the concentration of the unreactive aggregates increases, and this increase is stronger for the less-polar solvents, the polymerization rates tend to converge, such that at $[\mathrm{I}]_{0}=0.1 \mathrm{moll}^{-1}$ the $r_{\mathrm{p}}$-values measured in $\mathrm{C}_{6} \mathrm{H}_{6}$, THF and $\mathrm{CH}_{3} \mathrm{CN}$ become almost identical (Figure 1.10). $\mathrm{CH}_{3} \mathrm{CN}$ is the most polar of the three solvents used, and apparently breaks down the aggregates. Thus, within the studied range of concentrations the active species are mostly unimeric (i.e. reactive). In both THF and $\mathrm{C}_{6} \mathrm{H}_{6}$ the equilibrium 
between aggregated (unreactive-dormant) and nonaggregated species persists, although at the sufficiently low concentration for a given system the fraction of aggregated species may be negligibly small and no longer important. Both, the alkoxide active center and lactone molecule have dipolar structures. An analysis of the influence of the solvent dielectric constant, as the macroscopic parameter, on the $k_{\mathrm{p}}$ (the dipolar molecule-dipolar molecule reaction) in terms of the electrostatic effects, shows that increase in $\varepsilon$ should lead to a higher value of $k_{\mathrm{p}}$ In the analyzed case, however, a reverse order is observed, namely $k_{\mathrm{p}}$ in $\mathrm{CH}_{3} \mathrm{CN}$ is lower than in THF and benzene. Such behavior may be related to the specific solvation of the growing dialkylaluminum alkoxide by the dipolar solvents (i.e. THF, $\mathrm{CH}_{3} \mathrm{CN}$ ), both of which are sufficiently strong in their ground state, and increase $\Delta H_{\mathrm{p}}^{\neq}$in this way. It appears that these specific solvation effects prevail over the electrostatic field effects, with the net result being a decrease in $k_{\mathrm{p}}$ while increasing polarity and solvating power of the solvent is observed.

The exchange rates between aggregated (dormant) and unimeric (propagating) species in the CL/ $\mathrm{R}_{2} \mathrm{AlOR}$ system are sufficiently high as to govern even the growth of all macromolecules, as can be judged from the $M_{w} / M_{\mathrm{n}}$ values determined for the resulting poly(CL) being in the range from 1.03 to 1.13 [116].

Equation $1.38 \mathrm{~b}$ allows $k_{\mathrm{p}}$ and $K_{\mathrm{a}}$ to be determined for several other systems (including the anionic polymerization of $\mathrm{EO}$ and $\mathrm{D}_{3}$ ), that previously had been analyzed using numerical calculations [158]. Szwarc et al. indicated that such an analytical solution should exist, and discussed in more detail the problems of aggregation in anionic polymerizations and the related kinetic consequences [159].

It is worth adding at this point that, in the context of the aggregation phenomena observed in propagation, some initiators which are applied in the coordination polymerization, and eventually are transformed into the covalent active species, are known to exist mostly in the aggregated (dormant) forms. For instance, $\mathrm{Al}\left(\mathrm{O}^{i} \mathrm{Pr}\right)_{3}$ is known to form both trimeric $\left(\mathrm{A}_{3}\right)$ and tetrameric $\left(\mathrm{A}_{4}\right)$ aggregates; subsequent ${ }^{1} \mathrm{H}$ NMR and kinetic measurements revealed that, in the polymerization of CL $[160,161]$ initiated with a mixture of $A_{3}$ and $A_{4}$ at ambient temperatures, the trimeric aggregate exclusively initiated polymerization. The ratio of the corresponding initiation rates $\left(k_{\mathrm{i}}\left(\mathrm{A}_{3}\right) / k_{\mathrm{i}}\left(\mathrm{A}_{4}\right)\right)$ was estimated as equal to $10^{3}$, with the propagation being complete before the tetrameric $\mathrm{Al}\left(\mathrm{O}^{i} \mathrm{Pr}\right)_{3}$ reacts to any observable degree. When polymerization comes to the living polymer-monomer equilibrium, the mostly unreacted $\mathrm{A}_{4}$ is introduced slowly into the polymer chains via alkoxide-ester group transesterification reactions. Eventually, therefore, due to these segmental exchange reactions between living macromolecules, there is only one population of macromolecules having the most probable distribution of molar masses.

When the $A_{3} / A_{4}$ mixture is used to initiate polymerization at a sufficiently high temperature-that is, under conditions where the rate of interexchange between $A_{3}$ and $A_{4}$ is at least as fast as initiation with $A_{4}$-the aggregation phenomena become of minor importance. This type of situation will occur in LA polymerizations carried out above $100^{\circ} \mathrm{C}[125]$. 


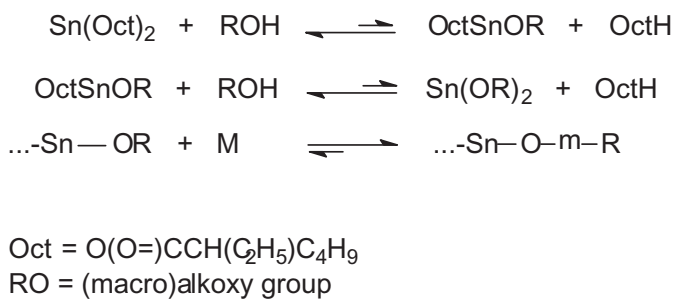

Scheme 1.4 Mechanism of cyclic esters polymerization initiated by $\mathrm{Sn}(\mathrm{II})$ octoate.

Sn(II) Octoate-Initiated Polymerization In a series of kinetic studies it has been shown that, during processes employing tin octoate $\left[\mathrm{Sn}(\mathrm{Oct})_{2}\right]\left(\mathrm{Sn}\left[\mathrm{O}(\mathrm{O}=) \mathrm{CCH}\left(\mathrm{C}_{2}\right.\right.\right.$ $\left.\left.\mathrm{H}_{5}\right) \mathrm{C}_{4} \mathrm{H}_{9}\right]_{2}$ ), the actual initiator and then the active center-Sn(II) alkoxide is formed reversibly in the alkoxy-carboxylate ligand interexchange reaction at the $\mathrm{Sn}$ atom (Scheme 1.4) [162-169]. The (macro)alcohol species can therefore be treated as being temporarily terminated dormant.

The formation of $\mathrm{Sn}(\mathrm{II})$ alkoxide from $\mathrm{Sn}(\mathrm{Oct})_{2}$ and an alcohol is a reversible reaction. Although the rates of exchange and the position of equilibria have not yet been established, the activation-deactivation reactions must be relatively rapid since, for up to $\approx 80 \%$ of the monomer conversion at $80^{\circ} \mathrm{C}$ in THF solvent the $M_{w} / M_{n}$ dispersity index is less than 1.2 [169], while the molar masses of polyester can be predicted from the $\left([\mathrm{M}]_{0}-[\mathrm{M}]\right) /[\mathrm{ROH}]_{0}$ ratio $[162,163]$. The influence of this interconversion on the polymerization kinetics can be approached in two ways, as shown in Scheme 1.4.

The example shown in Figure 1.12 compares the rates of LA polymerization in two systems: one system initiated with $\mathrm{Sn}(\mathrm{Oct})_{2} / \mathrm{BuOH}$, and another with $\mathrm{Sn}(\mathrm{OBu})_{2} / \mathrm{OctH}$ [98]. Polymerization with $\left[\mathrm{Sn}(\mathrm{Oct})_{2}\right]_{0}=0.05 \mathrm{moll}^{-1}$ but without added alcohol is very slow (plot 1), and is coinitiated by compounds containing hydroxyl groups (which adventitiously are present in the system as impurities). Polymerization initiated with $\left[\mathrm{Sn}(\mathrm{OBu})_{2}\right]_{0}=0.05 \mathrm{moll}^{-1}$ was $2.4 \times 10^{2}$ times faster than that with $\mathrm{Sn}(\mathrm{Oct})_{2}$ 'alone' (plot 4). In the next two experiments, the $\left[\mathrm{Sn}(\mathrm{Oct})_{2}\right]_{0}$ and $\left[\mathrm{Sn}(\mathrm{OBu})_{2}\right]_{0}$ were equal, while $0.05 \mathrm{moll}^{-1}$ and $0.1 \mathrm{moll}^{-1}$ of $\mathrm{BuOH}$ and OctH were added, respectively. As shown in plots 2 and 3 of Figure 1.12, the polymerization rates in the $\mathrm{Sn}(\mathrm{Oct})_{2} / \mathrm{BuOH}$ and $\mathrm{Sn}(\mathrm{OBu})_{2} / \mathrm{OctH}$ systems were practically the same, thereby strongly supporting the proposed polymerization mechanism noted in Scheme 1.4.

It should be added (notably with regards to the discussions in Sections 1.3.2.1 and 1.3.2.2) that, in the vast majority of recently reported kinetic studies of the ROP of heterocyclic monomers, the first internal order in monomer was observed; that is, the experimental plots of $\ln \left\{\left([\mathrm{M}]_{0}-[\mathrm{M}]_{\mathrm{eq}}\right) /\left([\mathrm{M}]-[\mathrm{M}]_{\mathrm{eq}}\right)\right.$ versus time were linear (Equation 1.29). Atypically, in LA polymerization initiated with zinc alkoxide bearing 2-(2-methoxyphenyl)amino-4-(2-methoxyphenyl)imino-2-pentene bidendate ligand, the second internal order in LA was observed (based on linearity of the $(1 /[\mathrm{LA}])-\left(1 /[\mathrm{LA}]_{0}\right)$ versus time plot). However, the mechanistic explanation of this result has not been provided [170a]. 


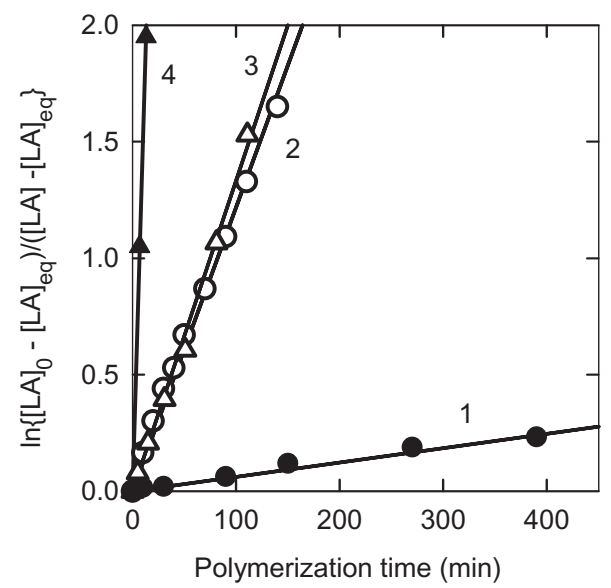

Figure 1.12 Comparison of kinetics of L,L-lactide (LA) polymerization initiated by tin octoate $\left(\mathrm{Sn}(\mathrm{Oct})_{2}\right)$ (line 1), $\mathrm{Sn}(\mathrm{Oct})_{2} / \mathrm{BuOH}$ (line 2), $\mathrm{Sn}(\mathrm{OBu})_{2} /$ octanoic acid $(\mathrm{OctH})$ (line 3) and $\mathrm{Sn}(\mathrm{OBu})_{2}$ (line 4). Conditions: $[\mathrm{LA}]_{0}=1.0 \mathrm{moll}^{-1}$, $\left[\mathrm{Sn}(\mathrm{OBu})_{2}\right]_{0}=\left[\mathrm{Sn}(\mathrm{Oct})_{2}\right]_{0}=0.05 \mathrm{moll}^{-1}$, $[\mathrm{OctH}]_{0}=[\mathrm{BuOH}]_{0}=0.10 \mathrm{moll}^{-1}$, THF solvent, temperature $50{ }^{\circ} \mathrm{C}[98]$.

Most often, the external orders in initiator $m \leq 1$ have also been reported. As discussed above, $m=1$ corresponds to a propagation on one type of active center of a given reactivity formed quantitatively from an initiator, whereas $m<1$ can be related to aggregation into species of lower reactivity than that of the unimeric, nonaggregated species (Equation 1.38a; $r_{\mathrm{p}} \sim[\mathrm{I}]_{0}{ }^{1 / \mathrm{m}}$ ) or the dissociation of ion pairs into the otherwise more reactive ions (Equations 1.29 and 1.35 for $k_{\mathrm{p}}^{-} \gg k_{\mathrm{p}}^{ \pm}$give $\left.r_{\mathrm{p}} \sim[\mathrm{I}]_{0}^{1 / 2}\right)$.

An external order in initiator $m>1$ poses certain interpretive problems. One possibility is that aggregates are more reactive than the parent unimeric species. Another explanation was proposed in Ref. [170b], though this stated that a certain concentration of adventitiously present impurities must be subtracted from $[\mathrm{I}]_{0}$, allowing the value of $m=1$ to be obtained. In contrast, in a situation when $D P_{\mathrm{n}}$ is easily predictable from the $\left([\mathrm{M}]_{0}-[\mathrm{M}]\right) /[\mathrm{M}]_{0}$ ratio, the latter solution could not easily be accepted.

\subsubsection{Departure from Livingness: Kinetics of Selected Side Reactions}

1.3.2.3.1 Cationic Polymerization The kinetics of termination, chain transfer and macrocyclization processes in cationic ROP have been extensively reviewed in Chapter 5 of Ref. [3a] and also in Ref. [74]. Of particular value is Table 18 in Ref. [3a], which details the basic equations in nonstationary kinetics with chain transfer. Although, since these two reviews were published few new phenomena have been identified, we will at this point provide a brief description of activated monomer cationic polymerization. 
In cationic polymerization, the chain-transfer side reactions cannot be avoided because nucleophilic sites of the monomer molecules (heteroatoms) are still present along the chain. Indeed, in some cases (e.g. cyclic acetals: dioxolane or trioxane) the nucleophilicity of an oxygen atom is higher when located in a polymer chain than when in a monomer molecule. As mentioned in Section 1.2.3, one particularly undesirable reaction is that of back-biting, which leads to the macrocyclics fraction (see Scheme 1.1). The extent of the back-biting reaction depends on the relative nucleophilicities of the heteroatom in a monomer molecule and in polymer unit, as well as on steric factors. In the polymerization of THF, the backbiting is slow when compared to propagation, and thus the macrocyclics fraction can easily be eliminated in a kinetically controlled synthesis [3b]. In contrast, in the cationic polymerization of EO, the typically predominant product is a cyclic dimer (1,4-dioxane), whereas in the cationic polymerization of substituted oxiranes (propylene oxide, epichlorohydrin), other cyclic oligomers (trimers, tetramers) are formed in significant amounts.

During the early 1980s, the cationic polymerization of cyclic ethers in the presence of low-molecular-weight diols as chain-transfer agent was studied with the aim of preparing polyether diols [82]. A more detailed investigation of this process revealed that the addition of alcohols to the polymerization of some oxiranes reduced the proportion of cyclics which was known to be formed by back-biting. The explanation for this observation was based on the activated monomer (AM) mechanism shown in Scheme 1.5 [171, 172].

In polymerization proceeded by an AM mechanism, the active centers are located on the monomer molecule (thus activated monomer), while the growing polymer chain is neutral, despite terminating with a reactive hydroxyl group. Because in the cationic AM mechanism there is no active species at the chain end, the back-biting is greatly reduced.

Even if the AM mechanism operates in a cationic polymerization of oxiranes in the presence of hydroxyl groups, it does not eliminate the possible contribution of a conventional active chain end (ACE) mechanism (active center; oxonium ion located at the macromolecular chain end). In order for an AM-type propagation to prevail, the instantaneous concentration of monomer should be kept as low as possible (e.g. via continuous slow monomer addition).

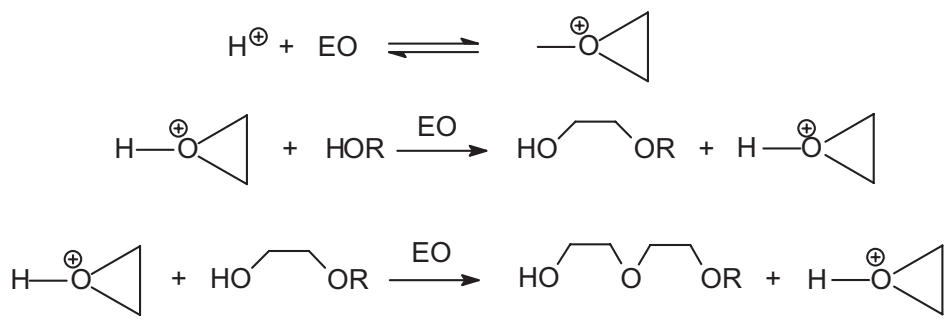

counterion omitted

Scheme 1.5 Polymerization of ethylene oxide (EO) according to the activated monomer mechanism. 
The kinetic studies, which were based exclusively on the determination of monomer consumption, allowed only an apparent rate constant to be determined (Equation 1.39).

$$
-\frac{d[\mathrm{M}]}{d \mathrm{t}}=k_{\mathrm{p}}^{\mathrm{app}}\left[\mathrm{H}-\mathrm{M}^{+}\right][\mathrm{HOR}]_{0}
$$

where $\mathrm{H}-\mathrm{M}^{+}$denotes a protonated monomer and $[\mathrm{HOR}]_{0}$ the starting alcohol concentration.

At low monomer conversion (almost no polymer present) it may be assumed that protons are distributed between oxygen atoms of monomer and hydroxyl groups only:

$$
\left[\mathrm{H}-\mathrm{M}^{+}\right]\left[{ }^{+} \mathrm{H}_{2} \mathrm{O}-\ldots\right]=K_{e} \frac{[\mathrm{HOR}]_{0}}{[\mathrm{M}]}
$$

In such a case, the sum of concentrations of protonated species is equal to the protonic acid concentration in the feed. Finally, combining Equations 1.39 and 1.40 gives Equation 1.41.

$$
\frac{\left[\mathrm{H}^{+}\right]}{d[\mathrm{M}] / d t}=\frac{1}{k_{\mathrm{p}}^{\text {app }}}+\frac{K_{\mathrm{e}}}{k_{\mathrm{p}}^{\text {app }}} \frac{[\mathrm{HOR}]_{0}}{[\mathrm{M}]}
$$

Thus, by plotting the results of the kinetic measurements $\left(\left[\mathrm{H}^{+}\right] / d[\mathrm{M}] / d \mathrm{t}\right)$ at early stages of polymerization on various $[\mathrm{ROH}]_{0} /[\mathrm{M}]$ ratios, we have a direct access to both $k_{\text {app }}$ and $K_{\mathrm{e}}[173,174]$. More detailed information on AM kinetics are available in a recent review (and references cited therein) [172].

1.3.2.3.2 Anionic and Coordinated Polymerization The alkoxide active centers in the polymerization of oxiranes, and carboxylate active centers in the polymerization of $\beta$-lactones, are not only nucleophilic but also sufficiently basic to abstract protons from the monomer molecule, and this eventually results in an irreversible chain transfer to monomer.

The transfer to monomer makes impossible the anionic polymerization of propylene oxide (PO; 2-methyl oxirane) to a high-molar-mass polymer (see e.g. Ref. [175] and references cited therein). However, it has been shown recently that the polymerization of PO initiated with alkaline metal alkoxides in hydrocarbon solvents can be accelerated substantially in the presence of a more than threefold molar excess of trialkylaluminum $\left(\mathrm{AlR}_{3}\right)$, with regards to the alkoxide initiator. The chain transfer is also strongly reduced, and this allows the controlled preparation of poly(PO) up to $M_{n} \geq 2 \times 10^{4}$. The role of the added $\mathrm{AlR}_{3}$ was explained by assuming activation of both the PO monomer and the alkoxide growing species, and in this way the selectivity of the propagation versus transfer $\left(k_{\mathrm{p}} / k_{\mathrm{tr}}\right)$ could be increased [176].

The anionic polymerization of $\beta$-substituted, four-membered lactones (e.g. BL) with alkaline metal counterions also suffers from a proton-abstraction side 
reaction, leading to a chain transfer to polymer $[177,178]$. The application of $\mathrm{Bu}_{4} \mathrm{~N}^{+}$ as a counterion resulted in an enhancement of the $k_{\mathrm{p}} / k_{\mathrm{tr}}$ ratio and allowed the preparation of poly(BL) with $M_{n} \leq 2 \times 10^{5}$, although the molar masses could barely be controlled [179]. Kinetic studies, supported by $M_{n}$ measurements which allowed determination of the selectivity parameter $k_{\mathrm{p}} / k_{\mathrm{tr}}=4 \cdot 10^{4}$ for $\mathrm{PL}\left(\mathrm{K}^{+} / \mathrm{DBC}, \mathrm{CH}_{2} \mathrm{Cl}_{2}\right.$ solvent, $\left.20^{\circ} \mathrm{C}\right)$, and $k_{\mathrm{p}} / k_{\mathrm{tr}} \leq 2.0 \cdot 10^{2}$ for $\mathrm{BL}\left(\mathrm{K}^{+} / \mathrm{DBC}\right.$, THF solvent, $\left.20^{\circ} \mathrm{C}\right)$ [178]. Both electronic and steric effects of the methyl group proved to be responsible for a lower value of the $k_{\mathrm{p}} / k_{\mathrm{tr}}$ ratio in $\mathrm{BL}$, when compared to PL, an effect which was due (at least partially) to differences in the rate constants of propagation $\left(4 \times 10^{-3}\right.$ and $10^{-6} \mathrm{~mol}^{-1} 1 \mathrm{~s}^{-1}$ at $20^{\circ} \mathrm{C}$ in THF solvent, respectively).

The anionic polymerization of cyclic esters with higher-membered ring sizes (five and more) proceeds on the alkoxide active centers. Less-nucleophilic carboxylates are unable to initiate the polymerization of these weakly or medium strained monomers, while the relatively high nucleophilicity of the alkoxides gives rise to chain transfer to polymer with chain rupture side reactions (see Scheme 1.1). As discussed earlier in Section 1.2.3, only an intramolecular transfer will lead to a departure from livingness. The kinetic scheme of polymerization accompanied by chain-transfer reactions is shown in Equation $1.42 \mathrm{a}-\mathrm{c}$.

$$
\begin{aligned}
& P_{n}^{*}+M(1) \stackrel{k_{p}}{\rightleftharpoons} P_{d}^{*} P_{n+1}^{*} \\
& \mathrm{P}_{\mathrm{n}}^{*} \underset{k_{\text {-tr } 1(\mathrm{y})} \stackrel{k_{\mathrm{tr}}(\mathrm{y})}{\rightleftharpoons}}{\rightleftharpoons} \mathrm{P}_{\mathrm{n}-\mathrm{y}}^{*}+\mathrm{M}(\mathrm{y}) \\
& \mathrm{P}_{\mathrm{n}}^{*}+\mathrm{P}_{\mathrm{m}}^{*} \underset{\mathrm{k}_{\text {tr } 2}}{\stackrel{\mathrm{k}_{\mathrm{t} 2}}{\rightleftharpoons}} \mathrm{P}_{\mathrm{n}+\mathrm{z}}^{*}+\mathrm{P}_{\mathrm{m}-\mathrm{z}}^{*}
\end{aligned}
$$

The intramolecular process is relatively easy to study quantitatively, mainly because the products of the chain transfer are cyclic compounds, the concentration of which can be measured by using standard chromatographic methods. Thus, the propagation (Equation 1.42a) and formation of cyclic oligomers (1.42b) are competitive reactions which take place simultaneously.

Solution of the kinetic Equation 1.42 (taking into account only propagation and intramolecular transfer) for some monomers (e.g. CL) for which propagation is practically irreversible, gives Equation 1.43 [81].

$$
\beta=\frac{k_{\mathrm{p}}}{k_{\mathrm{tr} 1}(\mathrm{y})}=\frac{\ln \left([\mathrm{M}(1)]_{\mathrm{o}} /[\mathrm{M}(1)]\right)}{[\mathrm{M}(\mathrm{y})]_{\mathrm{eq}} \cdot \ln \left\{[\mathrm{M}(\mathrm{y})]_{\mathrm{eq}} /\left([\mathrm{M}(\mathrm{y})]_{\mathrm{eq}}-[\mathrm{M}(\mathrm{x})]\right)\right\}}
$$

where $\beta=k_{\mathrm{p}} / k_{\mathrm{tr} 1}(\mathrm{y})$ is the selectivity parameter showing how many elementary acts of propagation (at $[\mathrm{M}(1)]=1 \mathrm{moll}^{-1}$ ) are accompanied by one macrocyclization. In this way, the value of $\beta$ is a direct measure of selectivity of a given active center.

By using the described kinetic approach, the ratios of $k_{\mathrm{p}} / k_{\mathrm{tr} 1}$ were determined for a few initiating systems [95], whereby the ratio was seen to differ by a factor of up to $10^{3}$. The corresponding data are collected in Table 1.3. Here, two phenomena are involved, namely reactivity and steric hindrance. It is found that, the higher 
Table 1.3 Propagation rate constants $\left(k_{\mathrm{p}}\right)$ and the selectivity parameters $\left(\beta=k_{\mathrm{p}} / k_{\mathrm{tr}}\right)$ for the polymerization of $\varepsilon$-caprolactone $[95]^{a}$

\begin{tabular}{lcc} 
Active species & $\frac{\boldsymbol{k}_{\mathbf{p}}}{\mathbf{L m o l}^{-1} \mathbf{s}^{-1}}$ & $\boldsymbol{\beta}=\frac{\boldsymbol{k}_{\mathbf{p}} / \boldsymbol{k}_{\mathrm{tr}}}{\mathbf{L ~ m o l}^{-1}}$ \\
\hline$\ldots-\left(\mathrm{CH}_{2}\right)_{5} \mathrm{O}^{-} \mathrm{Na}^{+}$ & $\geq 1.70$ & $1.6 \times 10^{3}$ \\
$\ldots-\left(\mathrm{CH}_{2}\right)_{5} \mathrm{O}-\mathrm{Sm}\left[\mathrm{O}\left(\mathrm{CH}_{2}\right)_{5}\right)_{2}$ & 2.00 & $2.0 \times 10^{3}$ \\
$\ldots-\left(\mathrm{CH}_{2}\right)_{5} \mathrm{O}-\mathrm{Al}\left(\mathrm{C}_{2} \mathrm{H}_{5}\right)_{2}$ & 0.03 & $4.6 \times 10^{4}$ \\
$\ldots-\left(\mathrm{CH}_{2}\right)_{5} \mathrm{O}-\mathrm{Al}\left[\mathrm{CH}_{2} \mathrm{CH}\left(\mathrm{CH}_{3}\right)_{2}\right]_{2}$ & 0.03 & $7.7 \times 10^{4}$ \\
$\ldots-\left(\mathrm{CH}_{2}\right)_{5} \mathrm{O}-\mathrm{Al}\left[\mathrm{O}_{(}\left(\mathrm{CH}_{2}\right)_{5}-\ldots\right]_{2}$ & 0.50 & $3.0 \times 10^{5}$ \\
$\ldots-\left(\mathrm{CH}_{2}\right)_{5} \mathrm{O}-\mathrm{AlO}_{2} \mathrm{SB}^{b}$ & 0.35 & $\approx 10^{6}$ \\
\hline
\end{tabular}

a Polymerization conditions: $20^{\circ} \mathrm{C}$, THF solvent.

b Polymerization conditions: $80^{\circ} \mathrm{C}$, THF solvent, $\mathrm{SBO}_{2}:(S)-(+)-2,2^{\prime}$-[1,1'-binaphthyl-2,2'-diylbis(nitrylomethylidyne)]-diphenolate ligand (A. Duda and A. Kowalski, unpublished results). SB = Schiff's base.

the reactivity for species of comparable steric hindrance around growing species (e.g. Sm trialkoxide and Al trialkoxide), the lower the selectivity-as is often the case with other chemical reactions. If, on the other hand, the reactivity in propagation is the same but steric hindrance differs, then for higher sterically hindered species the selectivity is higher; this is the case with dialkylaluminum alkoxides. The best selectivity, however, was observed for a low-reactive $\mathrm{Al}$ alkoxide bearing a sterically demanding bidendate ligand, $(S)-(+)-2,2^{\prime}$-[1,1'-binaphthyl-2,2'-diylbis(nitrylomethylidyne)]-diphenolate. Due to the high selectivity, it was possible to prepare the well-defined LA/CL block copolymers by initiating CL polymerization with the living poly(LA) block [180]-an approach that previously was impossible, even when using the highly selective Al trialkoxide.

The rate constant of intermolecular transfer $\left(k_{\mathrm{tr} 2}\right)$ or, alternatively, the $k_{\mathrm{p}} / k_{\mathrm{tr} 2}$ ratio, can be determined on the basis of a change in molar mass distribution as a function of monomer conversion. First, the dependencies of $M_{w} / M_{n}$ on $\left([\mathrm{M}]_{0}-[\mathrm{M}]\right) /[\mathrm{M}]_{0}$ were computed numerically, assuming the corresponding kinetic scheme (Equation 1.42a and c) and various $k_{\mathrm{p}} / k_{\mathrm{tr} 2}$ values and starting concentrations $\left([\mathrm{M}]_{0}\right.$ and $\left.[\mathrm{I}]_{0}\right)$. The fitting of these simulated dependencies to the experimental data was then carried out, after which the $k_{\mathrm{p}} / k_{\mathrm{tr} 2}$ ratio was determined by choosing the best-fit curve [95-97, 99].

Figure 1.7 provides an example of such determinations for the LA/ $\mathrm{Sn}(\mathrm{OBu})_{2}$ system. The dotted and solid lines were computed assuming $k_{\mathrm{p}} / k_{\mathrm{tr} 2}=125$ and 200, 
respectively. These values point to the relatively high selectivity of the $\mathrm{Sn}$ (II) alkoxide active centers [98].

\subsubsection{Kinetics of Copolymerization}

Typically, the kinetics of ring-opening copolymerization is analyzed in terms of the four equations, set with all reactions being irreversible. The aim of a such an analysis is to determine the reactivity ratios: $r_{1}=k_{11} / k_{12}$ and $r_{2}=k_{22} / k_{21}$ by means of the approaches elaborated by Mayo and Lewis or Finneman and Ross, or perhaps by Kelen and Tudos. Provided that the homopolymerization rate constants $\left(k_{11}\right.$ and $\left.k_{22}\right)$ are known from the homopolymerization studies, under otherwise identical conditions-and assuming that the same values are valid in copolymerization (this is not necessarily true for ionic or coordination ROP) - the crosspropagation rate constants $\left(k_{12}\right.$ and $\left.k_{21}\right)$ can eventually be determined.

However, with the exception of copolymerization of the three- and/or fourmembered comonomers, the copolymerization of higher rings is expected to be reversible, such that four additional homo- or cross-depropagation reactions must be added (kinetic Equation 1.44). In such a situation, the traditional methods of kinetic analysis must be put 'on hold', as a numerical solving of the corresponding differential equations is necessary. Moreover, depending on the selectivity of the active centers, any reversible transfer reactions can interfere to various degrees with the copolymerization process. Thus, the kinetically controlled microstructure of the copolymer may differ substantially from that at equilibrium (cf. Section 1.2.4).

$$
\begin{aligned}
& \ldots-\mathrm{m}_{1} *+\bigodot_{\mathrm{M}_{1}} \frac{k_{11}}{\rightleftharpoons} \underset{k_{-11}}{\rightleftharpoons} \ldots-\mathrm{m}_{1} \mathrm{~m}_{1} \text { * } \\
& \ldots-\mathrm{m}_{1} *+\bigodot_{\mathrm{M}_{2}} \frac{k_{12}}{\underset{k_{-12}}{\rightleftharpoons}} \ldots-\mathrm{m}_{1} \mathrm{~m}_{2} * \\
& \ldots-\mathrm{m}_{2}{ }^{*}+\bigodot_{\mathrm{M}_{1}} \frac{k_{21}}{\frac{k_{-21}}{\rightleftharpoons}} \ldots-\mathrm{m}_{2} \mathrm{~m}_{1} * \\
& \ldots-\mathrm{m}_{2}{ }^{*}+\bigodot_{\mathrm{M}_{2}} \frac{k_{22}}{k_{-22}} \ldots-\mathrm{m}_{2} \mathrm{~m}_{2}{ }^{*}
\end{aligned}
$$

Instructive example of the copolymerization involving monomer propagating reversibly comes from the L,L-lactide (LA)/E-caprolactone (CL) comonomers pair $[181,182]$. Recent analysis of this copolymerization system, by means of the numerical integration method [183], revealed that the comonomers reactivity ratios can be controlled by the configuration of the active species [184]. Thus, using initiator of various stereochemical compositions a broad spectrum of copolymers 
having different microstructures: from gradient to more random could be prepared in a controlled way.

\section{4}

\section{Concluding Remarks}

In this chapter we have shown that studies of the thermodynamics and kinetics of ROP play an indispensable role in our understanding of polymerization mechanisms. The results of these investigations have helped to establish controlled polymerization conditions, allowing the preparation of polymers with required molar masses and microstructures. The presence of various heteroatoms within the macromolecular main chain introduces an almost infinite number of possible homopolymeric and copolymeric properties. A recent development has been the controlled synthesis of aliphatic polyesters, mostly via ROP, based on their potential applications as biodegradable thermoplastics or as biomedical polymers. Moreover, as some cyclic ester monomers are prepared from renewable resources, some of the examples provided here have related to the ROP of aliphatic cyclic esters.

Within the field of ROP there remain many unanswered questions, including the controlled synthesis of high-molar-mass poly( $\beta$-butyrolactone) with a sufficiently reactive yet selective initiator, the use of 'fast initiators' in lactide polymerization that function with high selectivity in the monomer/polymer melt, and identification of the mechanisms of organocatalytically prompted polymerizations. It is clear that the resolution of these problems will require a systematic and careful approach to kinetic studies.

\section{References}

1 Frish, K.C. and Reegen, S.L. (eds) (1969) Ring-Opening Polymerization, Marcel Dekker, New York, London.

2 Ivin, K.J. and Saegusa, T. (eds) (1984) Ring-Opening Polymerization, Elsevier Applied Science Publishers, London, New York.

3 (a) Penczek, S., Kubisa, P. and Matyjaszewski, K. (1980) Advances in Polymer Science, 37, 1;

(b) Penczek, S., Kubisa, P. and Matyjaszewski, K. (1985) Advances in Polymer Science, 68/69, 1.

4 Eastmond, G.C. Ledwith, A. Russo, S. and Sigwalt, P. (eds) (1989) Chain polymerization, Part I, in Comprehensive Polymer Science. The Synthesis, Characterization, Reactions \& Applications of Polymers, Vol. 3
Pergamon Press, Oxford, pp. 283-320 (Chapter 22), 457-569 (Chapters 31-37), 711-859 (Chapters 45-53).

5 Penczek, S. (ed.) (1990) Models of Biopolymers by Ring-Opening Polymerization, CRC Press Inc, Boca Raton, FL.

6 Brunelle, D.J. (ed.) (1993) Ring-Opening Polymerization. Mechanisms, Catalysis, Structure, Utility, Hanser Publishers, Munich, Vienna, New York, Barcelona.

7 Penczek, S. and Duda, A. (1993) Die Makromolekulare Chemie. Macromolecular Symposia, 67, 15-42.

8 (a) Mecerreyes, D., Jerome, R. and Dubois, P. (1999) Advances in Polymer Science, 147, 1;

(b) Steinbuechel, A. and Doi, Y. (eds) (2002) Biopolymers, Vol. 3b, Polyesters II. 
Properties and Chemical Synthesis, Wiley-VCH Verlag GmbH, Weinheim, pp. 327-430 (Chapters 11 and 12);

(c) Coulembier, O., Degee, P., Hedrick, J.L. and Dubois, P. (2006) Progress in Polymer Science, 31, 723.

9 Sanda, F. and Endo, T. (2000) Journal of Polymer Science, Part A: Polymer Chemistry, 39, 265.

10 Odian, G. (2004) Ring-opening polymerization, in Principles of Polymerization, 4th edn, John Wiley \& Sons, Inc., Hoboken, New Jersey, Chapter 7, pp. 544-618.

11 Penczek, S., Duda, A., Kubisa, P. and Slomkowski, S. (2007) Ionic and coordination ring-opening polymerization, in Macromolecular Engineering, Precise Synthesis, Material Properties, Applications, Vol. 1 (eds K. Matyjaszewski, Y. Gnanou and L. Leilbler), Wiley-VCH Verlag $\mathrm{GmbH}$, Weinheim, pp. 103-59 (Chapter 4).

12 Penczek, S., Cypryk, M., Duda, A., Kubisa, P. and Slomkowski, S. (2007) Progress in Polymer Science, 32, 247.

13 Bielawski, Ch.W. and Grubbs, R.H. (2007) Progress in Polymer Science, 32, 1.

14 Dainton, F.S. and Ivin, K.J. (1948) Nature, 162, 705.

15 Dainton, F.S. and Ivin, K.J. (1958) Quarterly Reviews of the Chemical Society, 12, 61.

16 (a) Tobolsky, A.V. (1957) Journal of Polymer Science, 25, 220;

(b) Tobolsky, A.V. (1958) Journal of Polymer Science, 31, 126.

17 (a) Tobolsky, A.V. and Eisenberg, A. (1959) Journal of the American Chemical Society, 81, 780;

(b) Tobolsky, A.V. and Eisenberg, A (1959) Journal of the American Chemical Society (1960), 82, 289.

18 Szwarc, M. (1956) Nature, 178, 1168.

19 Szwarc, M., Levy, M. and Milkovich, R. (1956) Journal of the American Chemical Society, 78, 116.

20 Szwarc, M. (1998) Journal of Polymer Science, Part A: Polymer Chemistry, 36 , IX-XV.

21 Sawada, H. (1976) Thermodynamics of Polymerization, Marcel Dekker, Inc., New York, pp. 131-52 (Chapter 7).
22 Ivin, K.J. and Busfield, W.K. (1988) Polymerization thermodynamics, in Encyclopedia of Polymer Science and Engineering (eds H.F. Mark, N.M. Bikales, C.G. Overberger, G. Menges and J.I. Kroschwitz), John Wiley \& Sons, Ltd, New York, Chichester, Brisbane, Toronto, Singapore, pp. 555-605.

23 Penczek, S. and Kubisa, P. (1993) Cationic ring-opening polymerization, in Ring-Opening Polymerization. Mechanisms, Catalysis, Structure, Utility (ed. D.J. Brunelle), Hanser Publishers, Munich, Vienna, New York, Barcelona, Ch. 2.

24 Slomkowski, S. and Duda, A. (1993) Anionic Ring-Opening Polymerization, in Ring-Opening Polymerization. Mechanisms, Catalysis, Structure, Utility (ed. D.J. Brunelle), Hanser Publishers, Munich, Vienna, New York, Barcelona, Ch. 3.

25 Saiyasombat, W., Molloy, W., Nicholson, T.M., Johnson, A.F., Ward, I.M. and Poshyachinda, S. (1998) Polymer, 39, 5581.

26 Elias, H.-G. (2005) Thermodynamics of polymerization, in Macromolecules Vol. 1: Chemical Structures and Syntheses, WileyVCH Verlag GmbH, Weinheim, Chapter 7, pp. 193-219.

27 Szymanski, R. (1992) Progress in Polymer Science, 17, 917.

28 Libiszowski, J., Kowalski, A., Szymanski, R., Duda, A., Raquez, J.-M., Degée, P. and Dubois, P. (2004) Macromolecules, 37, 52.

29 Evstropov, A.A., Lebedev, B.V., Kulagina, T.G., Lyudvig, E.B. and Belenkaya, B.G. (1979) Vysokomolekulyarnye Soedineniya Seriya A, 21, 2038.

30 Evstropov, A.A., Lebedev, B.V., Kiparisova, E.G., Alekseev, V.A. and Stashina, G.A. (1980) Vysokomolekulyarnye Soedineniya Seriya A, 22, 2450.

31 Bonetskaya, A.K. and Sukuratov, S.M. (1969) Vysokomolekulyarnye Soedineniya, A11, 532.

32 Evstropov, A.A., Lebedev, B.V., Kulagina, T.G. and Lebedev, N.K. (1982) Vysokomolekulyarnye Soedineniya Seriya A, 24, 568.

33 Lebedev, B.V., Mukhina, N.N. and Kulagina, T.G. (1978) Vysokomolekulyarnye Soedineniya Seriya A, 20, 1297.

34 Lebedev, B.V., Evstropov, A.A., Lebedev, N.K., Karpova, E.A., Lyudvig, E.B. and Belenkaya, B.G. (1978) 
Vysokomolekulyarnye Soedineniya Seriya A, 20, 1974.

35 Evstropov, A.A., Lebedev, B.V., Kiparisova, E.G. and Sheveleva, M.G. (1981) Vysokomolekulyarnye Soedineniya Seriya B, 23, 551.

36 Lebedev, B.V., Evstropov, A.A. and Kiparisova, E.G. (1983) Vysokomolekulyarnye Soedineniya Seriya A, 25, 1679 .

37 (a) Ostrovskii, V.E., Khodzhemirov, V.A. and Barkova, A.P. (1970) Doklady Akademii Nauk SSSR, 191, 1095; (b) Beaumont, R.H., Clegg, B., Gee, G., Herbert, J.B.M., Marks, D.J., Roberts, R. C. and Sims D. (1966) Polymer, 7, 401.

38 Dreyfuss, M.P. and Dreyfuss, P. (1965) Journal of Polymer Science A, 3, 3261.

39 van Ooteghem, D., Deveux, R. and Goethals, E.J. (1976) Journal of Polymer Science. Part C: Polymer Symposia, 56, 459.

40 Sosnowski, S., Libiszowski, J., Slomkowski, S. and Penczek, S. (1984) Die Makromolekulare Chemie. Rapid Communications, 5, 239.

41 Matsuo, J., Aoki, K., Sanda, F. and Endo, T. (1998) Macromolecules, 31, 4432.

42 Duda, A. and Penczek, S. (1990) Macromolecules, 23, 1636.

43 Kaluzynski, K. and Penczek, S. (1979) Die Makromolekulare Chemie. Macromolecular Chemistry and Physics, 180, 2289.

44 (a) Kaluzynski, K., Szymanski, S. and Penczek, S. (1991) Journal of Polymer Science, Polymer Chemistry Edition, 29, 1825;

(b) Penczek, S., Duda, A., Kaluzynski, K., Lapienis, G., Nyk, A. and Szymanski, R. (1993) Die Makromolekulare Chemie. Macromolecular Symposia, 73, 91.

45 Lee, C.L. and Johannson, O.K. (1966) Journal of Polymer Science A, 1(4), 3013.

46 Finke, H.L., Scott, D.W., Gross, M.E., Messerly, J.F. and Waddington, D. (1956) Journal of the American Chemical Society, 78, 5469.

47 Antonolovic, D., Shiner, V.J. and Davidson, E.R. (1988) Journal of the American Chemical Society, 110, 1375-81.
48 Grubbs, R.H. (2003) Handbook of Metathesis, Vol. 3, Wiley-VCH Verlag $\mathrm{GmbH}$, Weinheim.

49 Benson, S.W., Cruickshank, F.R., Golden, D.M., Haugen, G.R., O’Neal, H. E., Rodgers, A.S. et al. (1969) Chemical Reviews, 69, 279.

50 Dainton, F.S., Devlin, T.R.E. and Small, P.A. (1955) Transactions of the Faraday Society, 51, 1710.

51 Odian, G. (2004) Ring-opening polymerization, in Principles of Polymerization, 4th edn, John Wiley \& Sons, Ltd, Hoboken, New Jersey, Chapter 3, p. 281.

52 Shinno, K., Miyamoto, M., Kimura, Y., Hirai, Y. and Yoshitome, H. (1997) Macromolecules, 30, 6438.

53 Raquez, J.-M., Degee, P., Narayan, R. and Dubois, Ph. (2001) Macromolecules, 34, 8419.

54 Flory, P.J. (1953) Principles of Polymer Chemistry, Cornell University Press, Ithaca, NY, Chapters XII, XIII.

55 Ivin, K.J. and Leonard, J. (1970) European Polymer Journal, 6, 331

56 Penczek, S. and Matyjaszewski, K. (1976) Journal of Polymer Science Polymer Symposium, 56, 255.

57 Kress, H.-J., Stix, W. and Heitz, W. (1984) Die Makromolekulare Chemie. Macromolecular Chemistry and Physics, 185 173.

58 Huk, K.N., Jabbari, A., Hall, H.K. Jr, and Aleman, C. (2008) The Journal of Organic Chemistry, 73, 2674.

59 Duda, A., Penczek, S., Dubois, P., Mecerreyes, D. and Jerome, R. (1996) Macromolecular Chemistry and Physics, 197, 1273.

60 Duda, A., Biela, T., Libiszowski, J., Penczek, S., Dubois, P., Mecerreyes, D. and Jerome, R. (1998) Polymer Degradation and Stability, 59, 215.

61 Duda, A. and Penczek, S. (2000) American Chemical Society Symposium Series, 764, 160.

62 (a) Korte, F. and Glet, H. (1966) Journal of Polymer Science. Part C: Polymer Letters, 4, 685

(b) Zhulin, V.M., Makarova, Z.G. and Ignatenko, A.V. (1988) Doklady Akademii Nauk SSSR, 298, 1411. 
63 Ubaghs, L., Waringo, M., Keul, H. and Hoecker, H. (2004) Macromolecules, 37, 6755.

64 Agarwal, S. and Xie, X. (2003) Macromolecules, 36, 3545.

65 Penczek, S., Slazak, R. and Duda, A. (1978) Nature, 273, 738.

66 (a) Duda, A. and Penczek, S. (1982) Macromolecules, 15, 36.

(b) Duda, A., Szymanski, R. and Penczek, S. (1983) Journal of Macromolecular Science, AZO, 967.

67 Reif, R. and Hoecker, H. (1984) Macromolecules, 17, 952.

68 Pruckmayr, G. and Wu, T.K. (1978) Macromolecules, 11, 265.

69 (a) Miki, T., Higashimura, H. and Okamura, S. (1967) Journal of Polymer Science, Part A: Polymer Chemistry, 5, 2997;

(b) Chwialkowska, W., Kubisa, P. and Penczek, S. (1982) Die Makromolekulare Chemie. Macromolecular Chemistry and Physics, 183, 753.

70 Ito, K. and Yamashita, Y. (1978) Macromolecules, 11, 68.

71 Wichterle, O. (1960) Die Makromolekulare Chemie. Macromolecular Chemistry and Physics, 35, 127.

72 Chojnowski, J., Scibiorek, M. and Kowalski, J. (1977) Die Makromolekulare Chemie. Macromolecular Chemistry and Physics, 178, 1351.

73 Goethals, E.J., Simonds, R., Spassky, N. and Momtaz, A. (1980) Die

Makromolekulare Chemie.

Macromolecular Chemistry and Physics, 181, 2481.

74 Penczek, S. and Slomkowski, S. (1989) Chain polymerization, Part I, in Comprehensive Polymer Science. The Synthesis, Characterization, Reactions Q Applications of Polymers, Vol. 3 (eds G.C. Eastmond, A. Ledwith, S. Russo and P. Sigwalt), Pergamon Press, Oxford.

75 Jacobson, H. and Stockmayer, W.H. (1950) The Journal of Chemical Physics, $18,1600$.

76 Semlyen, J.A. (1976) Advances in Polymer Science, 21, 43.

77 Brown, J.F. and Slusarczuk, J.F. (1965) Journal of the American Chemical Society, 87, 931.
78 (a) Semlyen, J.A. and Wright, P.V. (1969) Polymer, 10, 643;

(b) Wright, P.V. (1973) Journal of Polymer Science, Polymer Chemistry Edition, 11, 51.

79 Sosnowski, S., Slomkowski, S., Penczek, S. and Reibel, L. (1983) Die Makromolekulare Chemie. Macromolecular Chemistry and Physics, 184, 2159.

80 Ito, K., Hashizuka, Y. and Yamashita, Y. (1977) Macromolecules, 10, 821.

81 Hofman, A., Slomkowski, S. and Penczek, S. (1987) Die Makromolekulare Chemie. Rapid Communications, 8, 387.

82 Kuzaev, A.I. and Olkhova, O.M. (1982) Vysokomolekulyarnye Soedineniya Seriya A, 24, 2197.

83 Szymanski, R. (1987) Die Makromolekulare Chemie. Macromolecular Chemistry and Physics, 187, 2605.

84 Szymanski, R. (1992) Progress in Polymer Science, 17, 917-51.

85 Szwarc, M. and Perrin, C.L. (1985) Macromolecules, 18, 528.

86 Szymanski, R. (1986) Macromolecules, 19, 3003.

87 (a) Szymanski, R. (1989) Die Makromolekulare Chemie. Macromolecular Chemistry and Physics, 190, 2903;

(b) Szymanski, R. (1991) Die Makromolekulare Chemie. Macromolecular Chemistry and Physics, 192, 2943;

(c) Szymanski, R. (1991) Die Makromolekulare Chemie. Macromolecular Chemistry and Physics, 192, 2961.

88 Szymanski, R. (1992) Die Makromolekulare Chemie. Theory and Simulations, 1, 129.

89 Duda, A., Libiszowski, J., Mosnacek, J. and Penczek, S. (2005) Macromolecular Symposia, 226, 109.

90 Mosnacek, J., Duda, A., Libiszowski, J. and Penczek, S. (2005) Macromolecules, 38, 2027-9.

91 Flory, P.J. (1940) Journal of the American Chemical Society, 62, 1561.

92 (a) Schulz, G.V. (1935) Zeitschrift für Physikalische Chemie, B30, 379;

(b) Flory, P.J. (1936) Journal of the American Chemical Society, 58, 1877.

93 Majerska, K. and Duda, A. (2004) Journal of the American Chemical Society, 126, 1026.

94 Duda, A. (1998) Polimery (Warsaw), 43, 135. 
95 Baran, J., Duda, A., Kowalski, A., Szymanski, R. and Penczek, S. (1997) Macromolecular Symposia, 123, 93.

96 Baran, J., Duda, A., Kowalski, A., Szymanski, R. and Penczek, S. (1997) Macromolecular Rapid Communications, 18, 325.

97 Penczek, S., Duda, A. and Szymanski, R. (1998) Macromolecular Symposia, 132 441.

98 Kowalski, A., Libiszowski, J., Duda, A. and Penczek, S. (2000) Macromolecules, 33, 1964.

99 Szymanski, R. (1998) Macromolecular Theory Simulations, 7, 27.

100 (a) Eyring, H. (1935) The Journal of Chemical Physics, 3, 107.

(b) Laidler, K.J. and King, M.C. (1983) The Journal of Physical Chemistry, 87, 2657.

101 (a) Gol'dfarb, Ya.I., Belen'kii, L.I. (1960) Russian Chemical Review, 29, 214;

(b) Huisgen, R. and Ott, H. (1959) Tetrahedron, 6, 253.

102 Sosnowski, S., Slomkowski, S. and Penczek, S. (1991) Die Makromolekulare Chemie. Macromolecular Chemistry and Physics, 192, 735.

103 Duda, A., Kowalski, A., Penczek, S., Uyama, H. and Kobayashi, S. (2002) Macromolecules, 35, 4266.

104 van der Mee, L., Helmich, F., de Bruin, R., Vekemans, J.A.J.M., Palmans, A.R.A. and Meijer, E.W. (2006) Macromolecules, 39, 5021.

105 Penczek, S., Duda, A., Szymanski, R. and Biela, T. (2000) Macromolecular Symposia, 153, 1.

106 Penczek, S. (2000) Journal of Polymer Science, Part A: Polymer Chemistry, 38, 1919.

107 Matyjaszewski, K. (1986) Journal of Macromolecular Science-Reviews in Macromolecular Chemistry and Physics, C26, 1.

108 Flory, P.J. (1940) Journal of the American Chemical Society, 62, 1561.

109 Flory, P.J. (1953) Principles of Polymer Chemistry, Cornell University Press, Ithaca, NY, p. 336.

110 Boileau, S., Champetier, G. and Sigwalt, P. (1963) Die Makromolekulare Chemie. Macromolecular Chemistry and Physics, 69, 180.
111 Boileau, S. (1981) American Chemical Society Symposium Series, 166, 283.

112 Slomkowski, S. and Penczek, S. (1976) Macromolecules, 9, 367.

113 Deffieux, A. and Boileau, S. (1976) Macromolecules, 9, 369.

114 Ouhadi, T., Hamitou, A., Jerome, R. and Teyssie, P. (1976) Macromolecules, 9, 927.

115 Dubois, P., Jerome, R. and Teyssie, P. (1989) Polymer Bulletin (Berlin), 22, 475.

116 Duda, A., Florjanczyk, Z., Hofman, A., Slomkowski, S. and Penczek, S. (1990) Macromolecules, 23, 1640.

117 Hashimoto, K. (2000) Progress in Polymer Science, 25, 1411.

118 Schlaad, I. and Dimitrov, H. (2003) Chemical Communications, 2944.

119 Aliferis, T., Iatrou, H. and Hadjichristidis, N. (2004) Biomacromolecules, 5, 1653.

120 Deming, T.J. (1997) Nature, 390, 386.

121 Goethals, E.J., Schacht, E.H., Bruggeman, P. and Bossaer, B.K. (1977) American Chemical Society Symposium Series, 59, 1.

122 Saegusa, T. and Kobayashi, S. (1976) Cyclic imino ethers polymerization, in Encyclopedia of Polymer Science and Technology, Suppl. Vol. 1 (eds H.F. Mark and N.F. Bikales), John Wiley \& Sons, Inc., New York, p. 220.

123 Kobayashi, S. and Uyama, H. (2002) Journal of Polymer Science Part A-Polymer Chemistry, 40, 192.

124 Dworak, A. (1998) Macromolecular Chemistry and Physics, 199, 1843.

125 (a) Kowalski, A., Duda, A. and Penczek, S. (1998) Macromolecules, 31, 2114; (b) Beste, L.F. and Hall, H.K., Jr (1964) The Journal of Physical Chemistry Edition, 68, 269.

(c) Pepper, D.C. (1980) European Polymer Journal, 16, 407.

(d) Penczek, S. and Libiszowski, J. (1988)

Die Makromolekulare Chemie.

Macromolecular Chemistry and Physics, 189, 1765

126 (a) Gold, J.L. (1958) The Journal of Physical Chemistry, 28, 91.

(b) Peebles, L.H., Jr (1971) Molecular Weights Distribution in Polymers, John Wiley \& Sons, Inc., New York, Washington DC, p. 137. 
127 Penczek, S., Kubisa, P. and Szymanski, R. (1991) Die Makromolekulare Chemie. Rapid Communications, 12, 77.

128 Matyjaszewski, K. and Penczek, S. (1974) Journal of Polymer Science, Polymer Chemistry Edition, 12, 1905.

129 Baran, T., Brzezinska, K., Matyjaszewski, K. and Penczek, S. (1983) Die Makromolekulare Chemie. Macromolecular Chemistry and Physics, 184, 2497.

130 Goethals, E.J. and Drijvers, W. (1973) Die Makromolekulare Chemie. Macromolecular Chemistry and Physics, $165,329$.

131 Goethals, E.J. and Schacht, E.H. (1973) Journal of Polymer Science, Polymer Letters Edition, 11, 479.

132 Saegusa, T., Kobayashi, S. and Yamada, A. (1976) Die Makromolekulare Chemie. Macromolecular Chemistry and Physics, 177, 2271.

133 Libiszowski, J., Szymanski, R. and Penczek, S. (1989) Die Makromolekulare Chemie. Macromolecular Chemistry and Physics, 190, 1225.

134 Szymanski, R. and Penczek, S. (1982) Die Makromolekulare Chemie. Macromolecular Chemistry and Physics, 183, 1587.

135 Matyjaszewski, K. (1984) Die Makromolekulare Chemie. Macromolecular Chemistry and Physics, 185, 51.

136 Penczek, S. and Duda, A. (1996) Macromolecular Symposia, 107, 1.

137 Florczak, M., Kowalski, A., Libiszowski, J., Majerska, K. and Duda, A. (2007) Polimery (Warsaw), 52, 722.

138 Brzezinska, K., Chwialkowska, W., Kubisa, P., Matyjaszewski, K. and Penczek, S. (1977) Die Makromolekulare Chemie. Macromolecular Chemistry and Physics, 178, 2491.

139 Matyjaszewski, K. and Penczek, S. (1981) Die Makromolekulare Chemie. Macromolecular Chemistry and Physics, 182, 1735.

140 Sosnowski, S., Duda, A., Slomkowski, S. and Penczek, S. (1984) Macromolecular Rapid Communications, 5, 551.

141 (a) Szwarc, M. (1968) Carbanions Living Polymers and Electron Transfer Processes,
John Wiley \& Sons, Inc., New York; (b) Szwarc, M. and van Beylen, M. (1993) Ionic Polymerization and Living Polymers, Chapman \& Hall, New York;

(c) Szwarc, M. (1996) Ionic Polymerization Fundamentals, Hanser, Munich.

142 Slomkowski, S. (1986) Polymer, 27, 71.

143 (a) Eizner, Yu.E. and Yerusalimskii, B.L. (1976) Electronic Aspects of Polymerization (in Russian), Nauka Pubishing House, Leningrad;

(b) Penczek, S., Kubisa, P. and Matyjaszewski, K. (1980) Advances in Polymer Science, 37, 52.

144 Sosnowski, S., Slomkowski, S. and Penczek, S. (1983) Journal of Macromolecular Science-Chemistry, A20, 735.

145 Goethals, E.J., Drijwers, W., van Ooteghem, D. and Buyle, A.M. (1973) Journal of Macromolecular ScienceChemistry, A7, 1375.

146 Matyjaszewski, K., Slomkowski, S. and Penczek, S. (1979) Journal of Polymer Science, Polymer Chemistry Edition, 17, 69.

147 Brzezinska, K., Matyjaszewski, K. and Penczek, S. (1978) Die Makromolekulare Chemie. Macromolecular Chemistry and Physics, 179, 2387.

148 Matyjaszewski, K. (1984) Die Makromolekulare Chemie. Macromolecular Chemistry and Physics, 185, 37.

149 Khanna, S.N., Levy, M. and Szwarc, M. (1962) Transactions of the Faraday Society, 58, 747.

150 Matyjaszewki, K. (ed.) (1996) Cationic Polymerization, Marcel-Dekker, New York.

151 (a) Braunecker, W.A. and Matyjaszewski, K. (2007) Progress in Polymer Science, 32, 93 ;

(b) Matyjaszewki, K. and Davis, T.P. (eds) (2002) Handbook of Radical

Polymerization, John Wiley \& Sons, Inc., Hoboken.

152 Boileau, S. (1989) Chain polymerization, Part I, in Comprehensive Polymer Science. The Synthesis, Characterization, Reactions Q A Applications of Polymers, Vol. 3 (eds G.C. Eastmond, A. Ledwith, S. Russo and P. Sigwalt), Pergamon Press, Oxford.

153 Kazanskii, K.S., Solovyanov, A.A. and Entelis, S. (1971) European Polymer Journal, 7, 1421. 
154 Wilczek, L. and Kennedy, J.P. (1987) Polymer Journal, 19, 531.

155 Penczek, S. and Duda, A. (1991) Die Makromolekulare Chemie. Macromolecular Symposia, 47, 127.

156 Duda, A. and Penczek, S. (1994) Macromolecular Rapid Communications, 15, 559.

157 Biela, T. and Duda, A. (1996) Journal of Polymer Science, Part A: Polymer Chemistry, 34, 1807.

158 Duda, A. and Penczek, S. (1994) Macromolecules, 27, 4867.

159 van Beylen, M., Bywater, S., Smets, G., Szwarc, M. and Worsfold, D.J. (1988) Advances in Polymer Science, 86, 87.

160 Duda, A. and Penczek, S. (1995) Macromolecular Rapid Communications, 16, 67.

161 Duda, A. and Penczek, S. (1995) Macromolecules, 28, 5981.

162 Kowalski, A., Duda, A. and Penczek, S. (1998) Macromolecular Rapid Communications, 19, 567.

163 Kowalski, A., Duda, A. and Penczek, S. (2000) Macromolecules, 33, 7359.

164 Majerska, K., Duda, A. and Penczek, S. (2000) Macromolecular Rapid Communications, 21, 1327.

165 Libiszowski, J., Kowalski, A., Biela, T., Cypryk, M., Duda, A. and Penczek, S. (2005) Macromolecules, 38, 8170.

166 (a) Storey, R.F. and Sherman, J.W. (2002) Macromolecules, 35, 1504.

(b) Messman, J.M. and Storey, R.F. (2004) Journal of Polymer Science Part A-Polymer Chemistry, 42, 6238.

167 Pack, J.W., Kim, S.H., Park, S.Y., Lee, Y.W. and Kim, Y.H. (2003) Macromolecules, 36, 8923.

168 Xian, C.-S., Wang, Y.-C., Chen, J.-Z., $\mathrm{Du}, \mathrm{X}$.-S. and Wang, J. (2006) Macromolecules, 9, 6825.

169 Penczek, S., Biela, T. and Duda, A. (2000) Macromolecular Rapid Communications, 21, 1941.

170 (a) Chen, H.-Y., Huang, B.-H. and Lin, C.-C. (2005) Macromolecules, 38, 5400; (b) Williams, C.K., Breyfogle, L.E., Choi, S.K., Nam, W., Young, V.C., Jr, Hillmyer, M.A. and Tolman, W.B. (2003) Journal of the American Chemical Society, 125, 11350.
171 Penczek, S., Kubisa, P., Matyjaszewski, K. and Szymanski, R. (1984) Structures and reactivities in the ring-opening and vinyl cationic polymerization, in Cationic Polymerizations and Related Processes (ed. E.J. Goethals), Academic Press, New York, p. 139.

172 Kubisa, P. and Penczek, S. (1999) Progress in Polymer Science, 24, 1409.

173 Biedron, T., Szymanski, R., Kubisa, P. and Penczek, S. (1990) Die Makromolekulare Chemie. Macromolecular Symposia, 32, 155.

174 Bednarek, M., Kubisa, P. and Penczek, S. (1989) Die Makromolekulare Chemie Supplement, 15, 49.

175 Yu, G.-E., Heatley, F., Booth, C. and Blease, T.G. (1994) Journal of Polymer Science Part A: Polymer Chemistry, 32, 1131.

176 Billuard, C., Carlotti, S., Desbois, P. and Deffieux, A. (2004) Macromolecular, 37, 4038.

177 Kricheldorf, H.R. and Scharnagl, N. (1989) Journal of Macromolecular Science-Chemistry, A26, 951.

178 Duda, A. (1992) Journal of Polymer Science, Part A: Polymer Chemistry, 30, 21.

179 Kurcok, P., Smiga, J. and Jedlinski, Z. (2002) Journal of Polymer Science, Part A: Polymer Chemistry, 40, 2184.

180 Florczak, M., Libiszowski, J., Mosnacek, J., Duda, A. and Penczek, S. (2007) Macromolecular Rapid Communications, 28, 1385.

181 Vanhoorne, P., Dubois, P., Jerome, R. and Teyssie, P. (1992) Macromolecules, 25 , 37.

182 (a) Kasperczyk, J. and Bero, M. (1991) Makromolekulare Chemie-Macromolecular Chemistry and Physics, 192, 1777.

(b) Kasperczyk, J., Bero, M. and Adamus, G. (1993) Makromolekulare ChemieMacromolecular Chemistry and Physics, 194, 907.

183 Chojnowski, J., Cypryk, M., Fortuniak, W., Rozga-Wijas, K. and Scibiorek, M. (2002) Polymer, 43, 1993.

184 Florczak, M. and Duda, A. (2008) Angewandte Chemie International Edition, 47, 9088. 
